\title{
LLNL REVIEW OF THE 1994 ACCELERATOR PRODUCTION OF TRITIUM (APT) CONCEPT
}

\author{
Dennis Slaughter \\ Review Chairman
}

H.P. Alesso, J.J. Barnard, R. Booth, M. Caplan, M.B. Chadwick, A.K. Chargin, F.S. Dietrich III, A. Faltens, J.M. Ferguson, E.M. Greybeck, J.M. Hall, W. Herrmannsfeldt, V.P. Karpenko, J.R. Kimbrough, M.N. Kreisier, S.V. Kulkarni, C.S. Landram, J.D. Lee, C.M. Logan, J.M. Mintz, T.L. Moore, M. J. Moran, W.E. Parker

C.T. Rockhold, K.E. Sale, J.A. Sefcik, W.J. Shotts, P.C. Wheeler, R.M. Yamamoto

University of California

Lawrence Livermore National Laboratory

Livermore, CA 94550

March 8, 1995

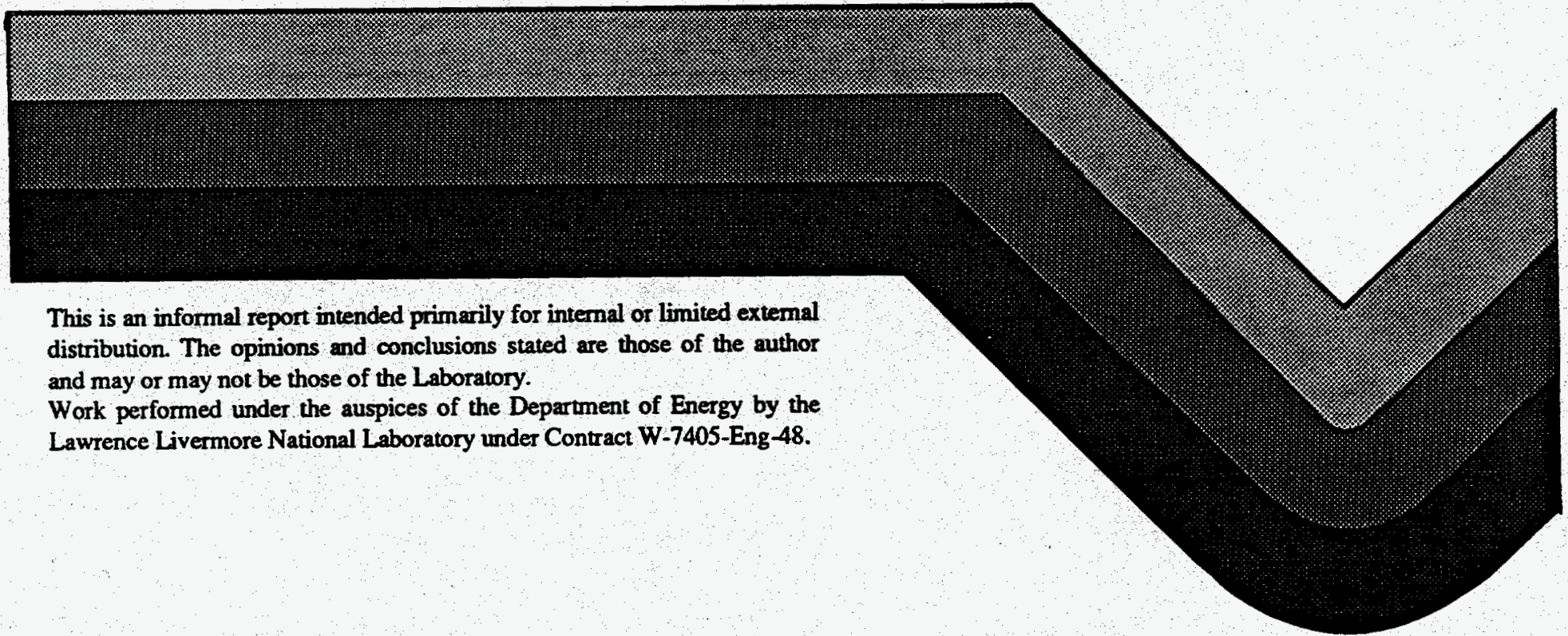




\section{DISCLAIMER}

This document wes prepared as an account of work sponsored by an agency of the United States Government. Neither the United States Government nor the University of Calfornia nor any of their employees, makes any warranty, express or implied, or assumes any legal Ihbllity or responsibility for the sccuracy, completeness, or usefulness of any information, apparatus, product, or process diselosed, or represents that its ase would not infringe privately owned rights. Reference herein to any pedife commercial products, process, or service by trade nane, trademark, manufacturer, or otherwise, does not neceasarily constitute or imply its endorseasent, recommendation, or fovoring by the United States Goverament or the University of Caffornia. The views and opinions of authors expressed berein do not necessarily atate or refiect those of the United States Government or the University of California, and shall not be used for advertising or product endorsement purposes.

This report has been reproduced directly from the best available copj.

Avallable to DOE and DOE contractors from the Onfice of Scientific and Technical Information P.O. Box 62, Oak Ridge, TN 37831

Prices avillable from (615) 576-8401, FTS 626-8401

Avallable to the public from the

National Technical Information Service

U.S. Department of Commerce

5285 Port Royal Rd.

Springfield, VA 22161 


\section{DISCLAIMER}

Portions of this document may be illegible in electronic image products. Images are produced from the best available original document. 


\title{
LLNL Review of the 1994 Accelerator Production of Tritium (APT) concept
}

\author{
Dennis Slaughter, Review chairman,
}

H. P. Alesso, J. J. Barnard, R. Booth, M. Caplan, M. B. Chadwick, A. K. Chargin, F. S. Dietrich III, A. Faltens (LBL), J. M. Ferguson, E. M. Greybeck, J. M. Hall, W. Herrmannsfeldt (SLAC), V. P. Karpenko, J. R. Kimbrough, M. N. Kreisler, S. V. Kulkarni, C. S. Landram, J. D. Lee, C. M. Logan, J. M. Mintz, T. L. Moore, M. J. Moran, W. E. Parker,

C. T. Rockhold, K. E. Sale, J. A. Sefcik, W. J. Shotts, P. C. Wheeler, R. M. Yamamoto

Executive Summary

Background and scope of the assessment

Conclusions

Recommendations

Appendices

A.......Detailed recommendations on accelerator concept 15

B....... Detailed recommendations on production target concept 19

C........ Detailed recommendations on risk and availability 25

D.......Detailed analysis of cost \& schedule $\quad 28$

E........Organization of the assessment 31

F.......Assessment meeting agenda and presenters 32

G........Bibliography of documents used to derive conclusions 34 


\section{Executive Summary}

LLNL was asked in September 1994 to review the accelerator production of tritium (APT) concept as it had evolved up to the fall of 1994. The purpose was not to compare it to other sources of tritium, but to identify possible technical flaws in the concept and to assess feasibility. A group of approximately 30 physicists and engineers was assembled from five LLNL directorates as well as accelerator designers from SLAC and LBL. This group reviewed in detail the design documents listed in Appendix G. Briefings were held at LLNL and BNL in October and November, and a four day workshop of presentations and small group meetings was held in December. Those presentations were followed by many small group meetings and conference calls during December and January to obtain details of the design proposed. Design calculations, methodologies, computer simulations, experimental data (raw and interpreted), elements of cost analyses, costing methodologies, and safety analyses were examined critically and in detail.

The APT concept reviewed was based on a $1.0 \mathrm{GeV}$ normal conducting proton linac operating CW at currents up to $200 \mathrm{~mA}$ with a target of tungsten and blanket of ${ }^{3} \mathrm{He}$ and lead. The LLNL review group concurs with the conclusions of four previous reviews (1989 to 1994) that this concept can meet the tritium requirements of a reduced stockpile of approximately $3500 \pm 1500$ warheads. We believe that the predicted tritium production rate is based on sound nuclear and transport models and that the schedules for technology demonstrations, design, and construction are realistic. We conclude that the technical risk of the concept is low and can be managed within the risk reduction program. The risk reduction program should focus on risk to the schedule and on cost reduction.

We are concerned that the design is based on production requirements that may be larger than is required for APT. The production requirement for tritium is based on experience with reactors that can be shut down or run at low power levels for extended periods because of safety concerns.

The present requirement for $100 \%$ excess capacity to replace the tritium rolling reserve within five years following a five year production hiatus adds approximately $400 \mathrm{M} \$$ to the APT construction cost. We recommend this requirement be re-examined considering reasonably expected operating scenarios appropriate for APT. The flexibility of accelerator technology will allow for varied production rates including operations modestly above the nominal capacity to compensate for lower production rates during reduced capacity operations. The tritium inventory is now well in excess of the requirement, but decays at a rate of about $5.6 \%$ per year. If APT production begins while the inventory is still in excess and is continuous from the beginning at a rate $5.6 \%$ above the annual requirement, the inventory will be maintained with a reserve equal to one year's production. On the other hand, if the inventory is maintained exactly at the mean requirement with no reserve, but there is a production hiatus of one year, a five year production cycle at $17 \%$ above the nominal requirement will replace the lost production.

Establishing the proper excess capacity margin for the APT facility should be addressed during the design process and we believe the proper margin is less than $100 \%$.

The requirement stated in the APT

Requirements Document stipulates $75 \%$ availability, i.e. full capability at least $75 \%$ of the scheduled production cycle. This requirement, generated in the Office of New Production Reactors, is inappropriate to accelerator operation and would lead to sub-optimal design. APT can operate at reduced capacity with some level of equipment failure between regular maintenance periods. Flexible production rates built into the design may be used to schedule tritium production based on varying needs. Varying production rates may be used to maintain reserves during optimum running periods such as when off-peak electrical power is available at 40$50 \%$ lower rates. That can produce a corresponding reduction in tritium production cost.

Having determined that the concept proposed can meet the requirement and do so on time, we find several technical areas in which the proposed design can be improved for higher availability and lower cost. RF cavity designs and choices in RF frequency have been based on proven experience, but they may not be optimal. We recommend re-examination of those designs 
for maximum electrical efficiency, and hence lowest operational cost, and for availability. We also recommend evaluation of super conducting technology in the high energy portion of the accelerator to reduce operational costs. Finally, we recommend multi-laboratory workshops where experts from the national accelerator community can provide input to optimization of the APT accelerator design.

We recommend experimental testing and demonstration of critical components such as the funnel, the ion source, and the production target/blanket. Testing target/blanket concepts is essential to properly scale the accelerator parameters and thus the construction cost of the facility. Uncertainties in today's nuclear models for the target are modest (5-20\%) but large enough to force costly design margins in the accelerator design. Improvements in the models will be an important part of optimizing the production target and in interpretation of its experimental testing.

Examination of the cost estimates for the APT construction and operation indicates that the construction cost has probably not been underestimated and may be up to $400 \mathrm{M} \$$ high, based on experience at other large accelerators. The operational cost is subject to uncertainties in electricity rates and labor rates that are difficult to predict over a 50 year term. Specifically, estimated component costs in the accelerator are slightly high. There is little experience on which to assess target/blanket cost estimates, but we find no serious errors. Cost estimates for the balance of plant were not evaluated in detail, but consider the contractor who prepared them experienced in this area. We found the contingencies in the cost estimates relatively high, but not inappropriate for a pre-conceptual stage of development. All of these estimates including accelerator components, contingencies, escalation rates, and peripheral costs will need reexamination as the design proceeds into the conceptual stage. It remains unclear why the burial depth is as large as it is and whether a less expensive approach would be viable.

Reliability analysis employed to date has been somewhat primitive and does not employ statistical distribution functions of component failures. A specific plan for daily operations and a plan for allocation of reliability among components can provide better predictions of availability and can lower cost of operation. These issues can be clarified as the APT undergoes a full conceptual design.

In summary, the review group finds the APT concept proposed to be viable for production of the $3 / 8$ goal quantity of tritium given in the current requirements, but feels the requirement to be inappropriate and to need reexamination. The schedule for design and construction is realistic. The technical risk in the concept is low, but there is modest risk in the schedule and uncertainty in cost that can be managed in a risk reduction program. Estimates of construction and operational costs are slightly ambiguous at this point, but a good risk reduction program can quantify and reduce them. 


\section{Background and scope of the assessment}

A proposal for the accelerator production of tritium (APT) has been developed by a consortium of three national laboratories, LANL, BNL, and SNL along with a group of industrial partners. The proposed accelerator facility is intended to generate spallation neutrons that breed tritium in targets containing ${ }^{3} \mathrm{He}$ or ${ }^{6} \mathrm{Li}$. The proposal has evolved over a number of years to meet the anticipated tritium requirement for the enduring nuclear weapons stockpile in the 21 st century. It provides a capacity for maintaining the equilibrium requirement for a stockpile of $3500 \pm 1500$ warheads, in addition to a surge production capability, that effectively doubles the tritium production capacity. This total requirement is known as the " $3 / 8$ goal", referring to the reduction in anticipated stockpile stipulated by international arms control treaties expected to be in place in the next century. Versions of the present proposal have been reviewed previously by ERAB in $1990^{1}, \mathrm{GAO}^{2}$ in 1991 , the JASONS group in $1992^{3}$, and by a recent MIT panel ${ }^{4}$.

The proposal is documented in several LANL reports describing the accelerator ${ }^{5-7}$, production target $5,8-14$, tritium extraction and processing 13,15 , isotope production 16,17 , balance of plant ${ }^{18}$, cost and schedule ${ }^{18,19}$, risk reduction program $5,14,20$, and safety issues 21 , 22.

In September 1994 LLNL was asked by DOE/DP to review the APT proposal. The review was directed toward determining whether there were potential technical flaws in the proposal. It was not directed toward evaluating alternative sources of tritium. Details of the proposal were provided in presentations given at a meeting described later. Its agenda including topics and presenters is given in Appendix $F$. The proposal consists of a pre-conceptual design for an RF excited proton accelerator, continuously delivering $200 \mathrm{~mA}$ beam current at $1.0 \mathrm{GeV}$ into one of two tritium production targets. The current concept envisions the production facility operating at these parameters for at least $75 \%$ of the production year to meet the tritium requirement. At this point many of the technical details are uncertain and will continue to evolve before development of a full conceptual design.

The assessment task was initiated by an overview presentation of the concept at LLNL on 17 October 1994 followed by accumulation of relevant documents cited in Appendix G. Details of the proposed concept contained in the cited documents were reviewed by about 20 physicists and engineers from many directorates at LLNL. These individuals committed about half of their time to this task over a period of approximately two months. Their names and organizations are listed in Appendix E. A small group of the assessment team visited BNL on 30 November 1994 to receive briefings on the SILC target design 23 and to discuss alternative APT concepts. This process culminated in a workshop consisting of presentations by LANL, BNL, SNL, and their industrial partners, outlining the details of the proposal to the LLNL team on 6-8 December 1994, and an informal visit with members of the APT accelerator design group at LANL on 9 December. The agenda, presentation titles, and presenters are given in Appendix F. These presentations have been followed up by numerous smaller meetings among professionals with expertise in accelerator design, RF technology, target design, thermal, hydraulic, and mechanical analysis, nuclear modeling, cost and schedule evaluation, Risk Availability and Maintainability (RAM) analysis, and ES\&H issues. Design calculations, methodologies, computer simulations, experimental raw and interpreted data, elements of cost analyses, costing methodologies, and safety analyses were examined critically and in detail over a period of approximately two months. The following sections describe the overall LLNL assessment of the concept contained in materials presented us. It is organized into a main body of conclusions and overall recommendations for development of the APT concept, followed by appendices containing detailed technical recommendations and assessments of the cost and schedule. 


\section{Conclusions}

1. An APT facility based on the $3 / 16$ goal design, plus engineering design margin, could provide sufficient tritium.

In particular, we find that:

a) The present statement of the tritium requirement appears to be based on experience with production reactors or some other contingency not clear to the review group and may be a needlessly demanding requirement for an APT facility.

b) Regeneration of a rolling reserve within 5 years after a 5 year down cycle effectively doubles the peak production rate requirement and may not be an appropriate requirement for an APT facility.

Operating experience with existing accelerators indicates that many component failures are predictable and provide ample warning signs. That allows component replacements to be part of regularly scheduled maintenance periods in many cases. Even when component failures occur unexpectedly, there is often no safety impact on the facility and production may continue in the presence of one or several major failures. Experience also indicates that most component failures in the accelerator can be repaired in relatively short time periods.

In considering experience with existing high-power accelerators over many years we find it improbable that the APT facility would be shut down for an extended period as a result of a component failure. No accident, failure, maintenance period, or facility upgrade has been described whose consequence would be a shut down of duration longer than one year. It then seems inappropriate to set a production rate requirement based on a five year period of nonproduction.

Even major accidents at the facility are likely to affect only a portion of the facility and experience indicates that repairs can be made quickly. Accelerator shut downs, when they occur, rarely exceed days or weeks. The production target is located in a confinement area where accidental release of radioactive material is restricted to one of two or more small volumes so that production could continue even if substantial repairs were required. Even if the facility was removed from production for a period as long as one year, decay of the total weapons tritium inventory during that time is only $5.6 \%$. The tritium inventory is now well in excess of the requirement. If APT production begins while the inventory is still in excess and is continuous from the beginning at a rate $5.6 \%$ above the annual requirement, the inventory will be maintained with a reserve equal to one year's production.

c) Any exaggeration of the true tritium requirement will artificially increase the cost of an APT facility.

Data presented indicates that the $3 / 8 \mathrm{goal}$ concept is more expensive than the $3 / 16$ goal concept by approximately $400 \mathrm{M} \$$ in total plant cost (TPC). Specification of the $3 / 8 \mathrm{goal}$ requirement should be evaluated considering this increase. If the requirement is based on anticipation of an unplanned shutdown of the production facility, a reliability and repair analysis should be carried out to determine the expected duration of shutdown. We believe that most accidental failures are not safety related and will not impose a significant hiatus in production. Consequently, the requirement that capacity be twice the normal production rate requirement seems excessive. A more realistic assessment of shut down scenarios may lead to more modest requirements on excess production capacity that could be satisfied either through increased design margin, or through construction of additional production facilities.

d) Some excess capacity in the APT design may allow more economical and reliable production of tritium

Provision for excess capacity in the APT design will allow tritium production to be scheduled during off-peak electrical demand periods so that electricity costs may be reduced up to $50 \%$. That can reduce the operational and life cycle cost of tritium production up to $40 \%$ as long as tritium production can be stopped during periods of peak electricity demand. 
There are a variety of approaches to establishing the proper design margin for excess production capacity to provide backup in case of a production shutdown. The nominal tritium production rate is $P_{0}$, given by $P_{0}=\lambda<1>$ where $\lambda$ is the tritium decay constant and $\langle l\rangle$ the nominal tritium inventory requirement. Suppose there is a production hiatus of duration $\mathrm{T}_{\mathrm{O}}$. Then tritium can be produced at an elevated rate, $(1+\alpha) \mathrm{P}_{0}$ to compensate for the loss of production either before hand or after the fact. During a compensation period $T$, the production rate $(1+\alpha) \mathrm{P}_{\mathrm{O}}$ can replace the lost production when the excess is given by the equation below.

$$
\alpha=\frac{1-e^{-\lambda T_{0}}}{e^{\lambda T}-1}
$$

Following a one year hiatus from production, the maximum that we think is credible, the lost production can be replaced within five years if an excess production margin of $17 \%$ is maintained. This can be accomplished with excess production before the hiatus, or immediately following the lost production. A similar analysis may be used to show that a $39 \%$ excess production rate for a five year period will not only replace the production loss during a one year shutdown, but will provide a one year reserve as well. The point of this is to indicate that excess capacity as large as $100 \%$ seems much more than needed for APT.

\section{On the basis of our assessment we concur with earlier reviews by ERAB ${ }^{1}$, GAO $^{2}$, JASONS $^{3}$, and a recent MIT panel ${ }^{4}$ that determined the Accelerator Production of Tritium concept can meet the stated tritium production requirements and that the technical risk is low.}

We concur with two of these reviews (JASONS and MIT) ${ }^{3,4}$ that the specific point design for a $3 / 8$ goal facility can meet the tritium requirements. The proposed APT accelerator is predicated on known modern accelerator designs and we find no major technical obstacles to its successful completion and operation. This assessment extends the endorsement to the proposal for a $3 / 16$ goal facility, although a proper evaluation awaits a fully documented point design.

Lower energy accelerators have produced beam currents in the range required for APT. One of the earliest accelerators for isotope production was the MTA facility (designed by $E$. $O$. Lawrence) at the present site of the LLNL in the early 1950s. It was an RF linac operating initially at $12 \mathrm{MHz}$ and later at $48 \mathrm{MHz}$ to accelerate beams to $40 \mathrm{MeV}$ and at currents up to $375 \mathrm{~mA}^{24}$, 25. It operated in $\mathrm{CW}$ mode at $70 \mathrm{~mA}$. Other ion sources such as RTNS-II at LLNL and an ion source developed by Chalk River Laboratory 26 have produced currents exceeding $100 \mathrm{~mA}$.

The target design is based on predictive tools that have been benchmarked in experiments at $\mathrm{LAMPF}^{27}, \mathrm{AGS}^{28}$ at BNL and elsewhere ${ }^{29}$. There are uncertainties in prediction of the tritium production rate, but they are not so large as to raise questions about feasibility or to indicate significant technical risk. The magnitude and impact of those uncertainties will be discussed in more detail later.

There is an engineering design margin of about $30 \%$ in the maximum available production capacity that could be invoked if necessary to cover what we currently consider to be reasonable uncertainty estimates in the target modeling and tritium recovery systems. If current target and recovery system production estimates turn out to be correct or conservative then this contingency could contribute to a modest increase in tritium production above the design value or to a less stringent demand for facility availability. Increasing the beam energy by the addition of accelerator sections could also be employed to increase the production rate. Larger increases in the tritium requirement might also be accommodated by construction of additional APT facilities.

3. The proposed schedule is realistic for timely production of required quantities of tritium provided the risk reduction program, the design, and construction phases are completed on time.

Other large accelerators have been constructed and brought to full operation on time scales similar to or shorter than the one presented. 
All the major components are either available commercially from more than one supplier, or are considered to be reasonable extrapolations in design from available components. To meet the schedule presented it is critically important that the risk reduction program be executed as proposed to incorporate results of that effort into more reliable and improved APT designs. It is also important that engineering design be carried out concurrently with the risk reduction program to allow starting construction on schedule. Finally, early industrial involvement in the design will be essential to assure success of the final production facility.

4. Predictions of tritium production
rate are based on state-of-the-art
calculations carried out with proper
attention to the details of the target
point design, but contain some
uncertainty.

Prediction of the tritium production rate is based on the estimated number of tritons produced per proton incident on the target at the design beam energy, for a given target design, estimated tritium extraction efficiency, and facility availability. These estimates are combined with the predicted average proton beam current to determine the facility production rate. The uncertainty in the accuracy of the predictions is difficult to estimate precisely, but it falls in a known range as discussed below.

a) Accelerator availability

All the large proton accelerator facilities currently operating provide beams for research where the requested beam power is often much less than the facility maximum capacity. It is difficult to determine their availability for full capacity operation on a year-round basis. Most major facilities operate within budget limits that constrain their operation to only a fraction (20-70\%) of a full year. Experience on LAMPF indicates availability of some quantity of beam current $80-100 \%$ of each shift during the scheduled running cycle. Our estimate of the uncertainty in APT availability based on extrapolation from LAMPF experience is 5$10 \%$. b) Estimate of the tritium production efficiency

Tritium production in the APT target/blanket assembly will ultimately be determined in an experimental simulation. Meanwhile, estimates are obtained from nuclear modeling of the production target using the LAHET Code System (LCS). This is a modeling tool used to optimize the target design and to predict the efficiency of converting high energy protons ( $p$ ) to thermal neutrons $(n)$ which are subsequently captured on ${ }^{3} \mathrm{He}$ or ${ }^{6} \mathrm{Li}$ to produce tritium (T). The conversion of $\mathrm{n}$ to $\mathrm{T}$ and the low energy neutron transport/thermalization is modeled with a data library based code, MCNP, which has been used extensively in reactor design and, except for possible uncertainties in the data base for materials not common in reactor applications, is believed to be adequate for APT target design.

The high energy spallation and energy loss processes are modeled in a nuclear reaction model code, LAHET. It is known to have deficiencies limiting the calculational accuracy to the order of $30 \%$ for many quantities of interest in the APT target modeling. There is experimental evidence that the accuracy may be somewhat better in the overall integral $n / p$ prediction for stopping (homogeneous, large compared to neutron mean free path) targets that fully contain all of the protons and neutrons.

i) $\mathrm{n} / \mathrm{p}$

As a starting point, we feel that it is of particular importance to evaluate the uncertainties in predictions of neutrons produced per proton, $n / p$, due to approximations in the underlying physics package for the interaction of high energy protons and neutrons with target materials. This can be done initially for assemblies that are essentially homogeneous and whose dimensions are large compared to the neutron mean free path.

There have been limited measurements of total neutron production in stopping targets at energies of interest using LAMPF 27,30 at $\mathrm{LANL}$, using $A G S$ at $B \mathrm{BL}^{31,32}$, at Dubna ${ }^{33}$, 34 and elsewhere 29,35 . These measurements 
fall into two categories. For assemblies large enough to fully contain the spallation cascade - . and thermalize almost all the neutrons the calculations reproduce experiments to better than the estimated errors 30,33 , which are about $5 \%$ for the Sunnyside experiment ${ }^{30}$. For assemblies with significant high energy neutron leakage, the predicted $n / p$ values are $15-20 \%$ higher than experiments 31,32 and direct measurements of high energy neutron leakage have shown a harder spectrum than predicted from LAHET ${ }^{33,34}$.

Correct prediction of the spatial distribution of thermal neutrons is important for predicting the tritium production rate in a complex structure such as the APT target, and energy deposition by high energy neutrons is important in thermal analysis of the target and beam stop. Therefore, while the APT target assembly overall is "low leakage", the transport of high energy particles within the stopping region and especially between the stopping region and the blanket needs to be accurately modeled to give confidence in the predicted $T / p$, and in analysis target cooling design, and materials damage.

\section{ii) $\mathrm{T} / \mathrm{p}$}

Errors in neutron transport and absorption in the different target and blanket zones may tend to cancel in the gross $T / p$ production rate. However, the target region contains a large amount of tungsten whose parasitic capture is reduced by the "flux trapping" technique, while the blanket of lead has low parasitic capture and design details are less important.

Lacking detailed sensitivity studies of the models or benchmark experiments on internal APT target operation, we can only conclude that the predictive uncertainty in nuclear modeling of tritium production probably falls in the range bounded by the $n / p$ results and the high leakage assemblies, $5-20 \%$. This uncertainty can be reduced and more clearly defined during the risk reduction program utilizing experimental code benchmarks and code improvements.

An experiment was conducted recently on LAMPF to measure the number of tritons produced per proton in a target assembly resembling the APT design. That experiment was presented to the assessment team by $G$. Morgan during the program summarized in Appendix $F$. There were a number of experimental difficulties and the data have not yet been fully interpreted. However, the preliminary results presented to us are consistent with the $-20 \%$ uncertainty estimate given above. Results of an improved experiment carried out during the risk reduction program, together with relevant experiments by others confirming the results would add considerably to our confidence in predicting APT tritium production.

c) Overall production uncertainties

The total uncertainty in tritium production combines accelerator, target and tritium recovery system performances. Overall, the assessment team can find no basis right now for assuming the accuracy of tritium production rate estimates is necessarily better than $30 \%$. At the same time we conclude that the predictive accuracy can be improved substantially in a well-designed risk reduction program and we recommend below some of the components of that program that would have significant impact.

Finally, we note that the point design presented has an engineering design margin approximately as large as the overall uncertainty that we believe is credible. Altematively, the extra capacity could be used for surge production or to reduce operating costs by running only during off-peak hours to take advantage of lower electricity costs.

5. We endorse the selection of the
${ }^{3}$ He target/blanket, with SILC as
backup, as a conservative design concept
whose yield can be predicted with
adequate precision.

The ${ }^{3}$ He target/blanket design presented is relatively new, but has been studied in some detail by computational modeling. It has four primary advantages over the backup SILC target/blanket design: 1) it has a smaller tritium inventory, 2) provides the simplicity of continuous extraction of tritium from a flowing gas stream, 3) uses a tungsten target rather than lead with a larger thermal margin so that 
meltdown and release of spallation products may be less likely, and 4) is less expensive to fabricate. The first two advantages are important since they reduce the potential ES\&H severity of an overheating accident in the target and reduce the impact on overall production in case one of the two targets is lost from production by an accident. Tritium extraction from the ${ }^{3} \mathrm{He}$ gas stream is technically simple and high extraction efficiency has been demonstrated in laboratory models. There is less hazardous waste generated in the target/blanket compared to the SILC design. Nevertheless, gas leaks in a pressurized ${ }^{3} \mathrm{He}$ gas flow system provide a mechanism for routine and/or accidental release of tritium into the target/blanket environment that must be avoided.

Production rates in the two target concepts appear to be roughly comparable at the same proton current and energy, with a slightly higher production rate in the ${ }^{3} \mathrm{He}$ design at the chosen beam energy of $1.0 \mathrm{GeV}$. In the event later design iterations have higher beam energies, above about $1.5 \mathrm{GeV}$, the relative production efficiencies should be compared carefully.

The SILC target/blanket design designated as backup was the first proposed and has two principal advantages over the ${ }^{3} \mathrm{He}$ design: 1) it is well matched to existing tritium handling facilities at Savannah River Laboratory, and 2) the tritium inventory is primarily in solid form rather than gas so that it is unlikely to be released without significant heating of the assembly. Nevertheless, in the case of a meltdown accident, the SILC target has a substantially larger tritium inventory than the ${ }^{3} \mathrm{He}$ concept and some potential for chemical reactions between hot aluminum and water so that its accident consequences are likely to be much more severe.

6. The estimated costs for APT
construction are not unrealistically low,
and could be up to $400 \mathrm{M} \$$ high, based
on experience at other large accelerators.
Operating cost has large uncertainty.

A detailed review of the cost estimates for construction and operation of the APT $3 / 8$ goal point design was carried out and the proposal values compared to recent experience on other large accelerators including SLAC, CERN, and
CEBAF. The review identified major cost areas and they are elaborated below.

a) The cost estimate for accelerator components may be high by $80 \mathrm{MS}$.

Most cost areas studied indicated that the LANL estimates were consistent with recent experience in accelerator construction at SLAC, CEBAF and CERN. Cost of components in the injector sections of APT seem appropriate, or at least, not unexpected. There are no good comparisons to be made for the cost of the high energy structure above $20 \mathrm{MeV}$. Recent cost experience has been with structures that are dramatically different than those proposed for APT and are not much use in performing comparisons. The estimated cost of RF power systems seems about $80 \mathrm{M} \$$ higher than recent experience procuring similar components for other large accelerators. There remain some uncertainties in the design and the details of components to be used that make a precise cost comparison difficult at this point in the preconceptual design process.

b) The accelerator burial depth and the size of the accelerator tunnel seem large compared to other comparable facilities and add up to $70 \mathrm{MS}$ in construction cost.

An accelerator tunnel with smaller inside diameter, such as used at CEBAF, was constructed at approximately $70 \mathrm{M} \$$ lower cost. If the burial depth were reduced sufficiently to allow trenching and covering rather than tunneling, there could be additional savings. These alternatives could be studied during the conceptual design process with the potential for reduction in construction cost.

c) There is little relevant experience with which the target/blanket assemblies' cost can be compared.

Fabrication cost of the target assemblies is relatively small compared to the TPC. Design costs could grow during the risk reduction program as alternative accelerator concepts are studied and alternative target designs carried out to support them. We believe that the estimated target/ blanket design and fabrication costs will be fixed by the results of the risk reduction program 
and are not likely to exceed those presented in the APT cost report.

d) The cost estimate for balance of plant was not studied in detail, but was prepared by a reputable contractor with experience in that area. The cost was deemed consistent with expectations and "rules of thumb" benchmarks for such facilities.

e) A contingency equal to $38 \%$ of estimated construction cost is generous for a facility judged to be low risk and may add up to $240 \mathrm{MS}$ to the estimated cost when compared to a more reasonable $25 \%$ contingency.

Large contingencies are common at the pre-conceptual stage of complex new projects based on developmental technologies. However, for the APT project the technical risk is low and major technology development not needed. The contingency included in the cost estimate, $718 \mathrm{M} \$$, corresponds to $38 \%$ of the capital costs (or $31 \%$ of TPC including the risk reduction program). We believe this contingency is larger than required.

The NIF project has a contingency equal to $23 \%$ of construction cost at the conceptual design stage following KD-1. The APT project is at the threshold of a conceptual design and is based primarily on proven technologies whose components are available commercially at known costs. A contingency closer to $25 \%$ would seem reasonable at this point and adopting that contingency would reduce the construction cost estimate by approximately $240 \mathrm{M} \$$. It is expected that the costs for construction will be defined with greater precision as the design matures and that the contingency requirement will be reduced by the risk reduction program and by the development of the conceptual design.

f) Predicting the operational cost of tritium production is very difficult and the uncertainties are large.

Approximately $80 \%$ of the operations cost of tritium production accrue from purchase of electricity. Rates for electricity purchase are difficult to predict now for purchases that will take place in the interval 2010 to 2050. Compounding the uncertainty is the choice of site and the design details that determine whether APT can meet its production goals using only interruptible or off-peak electrical supplies.
Finally, labor rates are difficult to forecast over a time scale of a half century. We believe a large uncertainty must be associated with the life cycle cost and operations cost estimates.

7. The point design presented to the
assessment panel is a viable solution,
but there may be potential for
improvements that provide cost
reduction.

A risk reduction program can be designed to provide design improvements that may increase the availability for tritium production and reduce schedule risk for completion, or reduce its cost. It is important that the risk reduction program scope and schedule be maintained to assure adherence to the schedule for on-time production.

8. A significant feature of APT is its
robust design where component failures
can be tolerated without interruption of
production, since most are not safety
related.

Many components such as klystron or other RF power sources fail predictably with adequate warning so that they can be repaired or replaced quickly during scheduled maintenance. Similarly, some beam diagnostics may fail without significant impact on equipment or personnel safety, and only modest degradation of APT operability. These failures generally do not affect facility safety and do not, in themselves, require tritium production to be interrupted. Proper design of the APT facility would allow substantial tritium production to continue, even at rates approaching full capacity, with one, or perhaps several, major component failures such as klystrons or RF power sources or some beam diagnostics.

9. We concur with conclusions
drawn in earlier reviews regarding the
ES\&H attractiveness of APT and the
technology choices made in the APT
point design presented.


Specifically, we concur with the ERAB ${ }^{1}$ and Jason' ${ }^{3}$ reviews on the following issues:

a) The APT concept is relatively attractive from an ES\&H point of view since there are no actinides used or produced in its operation. In addition, the decay heat produced in target components after facility shut-down is both short lived and manageable using conventional engineering design.

b) RF linac technology is more mature than high current induction accelerators, can provide higher beam currents than cyclotron technology, and is the proper technology choice for a low-risk APT design concept.

c) The $200 \mathrm{MW}$ beam power in the APT concept to meet the $3 / 8$ goal exceeds the experience obtained on any existing accelerator facility. At this time there is no experience with systems bringing together all the necessary combination of operating at high-current and high-energy. We nevertheless find no technical obstacles to successful operation of APT at the design parameters specified in the LANL presentations and the risk reduction program can establish a basis for confidence in the basic design. Activation of accelerator components from larger-than-expected beam emittance and instability growth are still possible, but they will be addressed experimentally to $40 \mathrm{MeV}$ in the risk reduction program, and computationally for higher energies. Furthermore, there are design features, including feedback and feed forward control systems, to help control the beam emittance growth.

d) There are no existing high power accelerators that are required to provide maximum power beams as much as $75 \%$ of the year. The high availability requirement in the APT concept exceeds previous experience, but can be attained through good engineering and a wellfocused risk reduction program. Nevertheless, we question the applicability of any specific availability requirement and recommend an alternative requirement in the recommendation's section later. e) Training of operational staff, operations procedures, human factors, and many other operational issues may be distinctly different in production vs. research facilities.

10. We find the principal safety
issues to involve risk to equipment and
production rather than to personnel.

Personnel safety is addressed primarily by prohibiting occupation of the facility interior spaces except during routine maintenance. Risk to equipment and degradation may be more complicated to control and to incorporate into design strategies and must be managed properly.

11. The risk to the schedule can be managed and reduced by demonstration of critical components during the risk reduction program.

We find no significant penalty in delaying critical design choices for the RF power sources, cavity designs, injector concept, or specific target design details to the end of the risk reduction program. In that way these designs can be improved based on testing and demonstrated performance. A significant reduction in schedule risk will be derived from the risk reduction program and there will still be adequate time to complete the facility design and initiate construction. Early industrial involvement during the risk reduction and conceptual design phases of the project will also reduce the risk to the schedule.

12. The assessment group did not assess the availability of adequate electrical power at candidate sites, as raised in the ERAB review ${ }^{1}$, nor did it compare the relative safety or cost of reactor production of tritium to APT.

In the following pages we detail specific recommendations regarding these conclusions and present details, in the appendices, for the designers of the concept. 


\section{Recommendations}

1. We recommend the tritium goal
requirement be reexamined and believe
that a $3 / 16$ goal with modest engineering
margin can meet the annual tritium
requirement.

The reasons behind this recommendation were discussed earlier among the conclusions. We believe that this reevaluation is important since a facility optimized for $3 / 8$ goal production is likely to be sub-optimal for 3/16 goal production. We further believe that the $3 / 16$ goal is sufficient to support stockpile requirements. This evaluation should be completed before facility design.

\begin{tabular}{l}
\hline We recommend that the "risk \\
reduction program" focus on three \\
issues: improving availability, reducing \\
uncertainty in schedule, and life-cycle \\
cost reduction.
\end{tabular}

Specifically, we recommend consideration of alternative technical concepts for RF linac design that would improve availability, have less schedule risk, and could result in lower construction or operating costs. The risk reduction program would then have the following objectives:

a) Reduce both the construction cost and operating cost of the APT concept.

i) It may be possible to improve the present point design(s) with regard to availability and operating cost.

ii) The design optimization process should not be constrained by fixed and individual requirements on availability, design margin, or maintenance. The principal constraint should be the average long-term tritium production rate (which is roughly proportional to beam joules delivered per year). iii) Possible improvements to the APT concept that may improve availability and reduce cost include alternative choices for beam current, final energy, RF operating frequency, RF sources, and super conducting technologies. These should be evaluated for possible incorporation into the final APT design.

iv) Target operating lifetime will have an impact on the operational cost of the APT facility. A surveillance program should be developed with the goal of establishing and extending component lifetime.

b) We recommend that, if the $3 / 16$ goal design continues to be studied, an optimized design for this concept be developed with sufficient detail for valid cost estimates to be developed.

c) The ground rules for deriving cost estimates may skew them. Using ground rules based on production reactors may, in some cases, be inappropriate for APT and lead to inflated estimates

The initial cost estimate seems to be based on DOE supplied labor rates $(\mathrm{M} \& \mathrm{O})$ and electricity costs that, in many instances, appear inappropriate to the candidate sites and estimated costs do not seem to be based on the point design currently being considered. A more realistic and accurate cost estimate is needed.

d) We recommend that elements of the risk reduction program that can be carried out on LAMPF be given high priority in LAMPF scheduling to ensure that they are executed on a timely basis.

e) We recommend a program of improvement in the models used to predict tritium production.

Uncertainties in modeling the tritium production of the APT are large enough to require relatively expensive engineering design margins 
in the facility concept. A series of benchmarks and validation tests of the models using assemblies constructed for LANSCE could be used to establish and reduce the target modeling uncertainties.

The physical models in LAHET are highly approximate due to the limited computational capability at the time these models were developed within the code. Incorporation of proper angular distributions and details of proton emission could improve the accuracy of Los Alamos Code System (LCS ) modeling of the APT target/blanket. Improvements in the cross section database could lead to more accurate spatial transport of the high energy neutrons produced in spallation. Experimental benchmarks could also play an important role in improving predictive accuracy for the tritium production in the APT target/blanket assembly.

Similarly, the accuracy of an MCNP calculation rests upon the quality of the underlying evaluated nuclear data bases, which currently extend only up to $20 \mathrm{MeV}$. LANL is currently investigating the accuracy of the databases for materials in the APT design, as well as for spallation products in the target. This is important for assessing the effects of parasitic neutron capture and its impact upon tritium production, and should be continued in the risk reduction. Nuclear data evaluation work to extend the databases for MCNP from 20 to 200 $\mathrm{MeV}$ during the risk reduction program would reduce uncertainties in the predicted number of neutrons. This would provide more accurate determinations of shielding requirements and heating effects. More specific recommendations on modeling improvements are given later in the section on target recommendations.

f) We recommend establishment of an independent panel of experts to monitor the design process and the risk reduction program on a continuing basis.

An oversight group reporting directly to DOE/DP could provide a useful vehicle for continuous external monitoring. Its function would be re-prioritization and redirection of the risk reduction program as it progresses toward final design and procurement. This process would provide another mechanism for early recognition and solution of problems as they arise, evaluation of priorities and reallocation of tasks as the project proceeds, and refereeing different points of view among lab partners. It could be a vehicle for invoking a much broader base of accelerator expertise from the national accelerator community and an unconflicted voice to the public and DOE management.

Membership should be selected carefully to represent broad technical areas, to establish nationally recognized stature, and some members should be intimately familiar with DP missions.

While the present point design is
adequate for meeting the tritium
requirement, we believe there are
opportunities to improve it. We
recommend one or more reference
designs optimized for maximum
availability and, to the extent possible,
minimum life-cycle cost.

New point designs should be developed to a sufficient level of detail to provide valid cost comparisons. Elements of the selection process for new point designs, including improvements due to alternative technologies for cavity design and provision of RF power, may be prioritized according to their potential for improved availability, schedule impact, and cost reduction.

We suggest the following starting points for prioritization:

a) Optimize the present concept of a 700 MHz room-temperature linac. It is recommended that this optimization include features such as those discussed at the review meetings by J. Billen, et. al. under the title "New Design Concepts for APT'.

b) A super conducting linac design probably featuring a somewhat higher beam energy, such as $1.5 \mathrm{GeV}$, where the neutron yield ratio (neutrons per proton-MeV) is better than at $1.0 \mathrm{GeV} . \mathrm{A}$ super conducting design would favor a higher energy solution.

During this review and after having been briefed on the contents of the review recommendations, the project management at LANL agreed to undertake a point design where the high energy part of the linac would be based on super conducting technology. We believe this is an important step in improvement of the APT concept. 
There may be an opportunity to reduce the APT construction and operating costs by introduction of super conducting technology into that part of the accelerator where proton energies exceed about $100 \mathrm{MeV}$. At the same time a risk estimate can be made to determine whether there is an improvement in facility availability resulting from potential design changes of this sort.

There is, nevertheless, some schedule risk since this approach is farther from demonstrated technology. An assessment must be made comparing the potential savings in cost (if any) against the schedule risk. In that context it would be important to assess the effect of heating and radiation damage of the super conducting surfaces due to beam halo, since those effects could obviate the advantages of this design. An assessment of accident scenarios including vacuum failure would also be important to determine response and to predict their impact on production.

c) Workshops could be convened during the design process where experts in super conducting technology and nuclear modeling could develop plans to improve the designs and the data bases used to model the performance of various designs.

The goal of the workshops could include improvements to and assessment of designs and tritium production predictions, and improvement of our understanding of design weaknesses and their uncertainties.

d) We concur with the plan to have multiple suppliers of RF sources to reduce technical and schedule risk.

We recommend that selection of RF source technology considers commercial availability from multiple vendors including US vendors. There is a risk to the schedule in development of any new source as called for in the present $3 / 8$ and $3 / 16$ goal proposals.

However, a higher efficiency RF source operating at lower voltage could provide advantages in both operating costs and overall system availability.

We recommend that the development of an advanced source be explored.

e) Introduction of a funnel to achieve 200 mA current capability may improve the facility availability of $100 \mathrm{~mA}$ operation, but : i) it is associated with some technical risk, and should be addressed in the risk reduction program.

ii) The funnel concept has the advantage of two available ion sources either of which can be used to generate $100 \mathrm{~mA}$ beams. This provides a reliability enhancement for operating scenarios where that current is sufficient.

4. We recommend re-examination of some premises that constrained the $3 / 8$ goal point design presented.

a) The requirement of $75 \%$ availability for the present point design is inappropriate and may lead to a design that is not optimum.

The most important requirement on the APT facility is its capacity to meet the tritium production goal over several years (the tritium half life of 12.1 years sets the time scale for production variations). One feature of the APT concept is its elasticity where minor design changes in beam current or beam energy result in significant variations in production rate. An optimum design may well employ high tritium production rates during short periods using interruptible or off-peak electrical power that is substantially cheaper and more readily available at the candidate sites. Such a design may run optimally at availability factors much less than $75 \%$.

We recommend changing the availability requirement of $75 \%$ stated in the requirements document ${ }^{36}$ to a much more flexible requirement that acknowledges the flexibility of APT production rates and the extent to which imposing an availability requirement may lead to a sub-optimal design of the facility. It was pointed out previously that modest increases in production capacity can be coupled advantageously with reduced or intermittent availability to reduce the cost of tritium production. 


\section{A philosophy should be defined and architecture developed for the control systems.}

Controls design reflects plant operation decisions and choices. Control systems definition and its architecture provide $a$ framework and discipline for project integration. To maximize the probability that subsystems will integrate properly into the overall APT controls structure, it must be defined. It is important that, as designs progress, the expectations on interfaces and control functionality be understood and properly accounted for by the subsystems' designers. Controls provide an integrating function across all subsystems, identifying potential incompatibilities earlier than may otherwise be discovered. Failure to keep a control's effort active during conceptual designing can lead to embarrassing discoveries in subsequent design reports and, in the worst case, can effect the commissioning schedule for the facility.

\begin{tabular}{|l|}
\hline 6. As design options for APT are \\
selected, a safety plan quantitatively \\
stating the hazards to equipment and \\
personnel should be developed.
\end{tabular}

The assessment group considers equipment protection to be a more difficult technical challenge than protection of personnel. Detailed estimates of radiation levels in areas where important components are located should be determined for well defined operational scenarios. Results of those evaluations can then be used in deriving improvements to the design that enhance availability.

Material presented to us was preconceptual. As the conceptual design is developed it is important to consider ES\&H issues as an integral part of the design process. To make relevant, reliable predictions of the annual production by APT, quantitative predictions of radiation levels, and exposure duration for personnel, will be need to be made. Among other things, accurate maintenance, repair and replacement schedules will require this information.

An integrated protection system should be defined for APT to help eliminate unnecessary system redundancy. For example, the beam diagnostics that are used to maintain the required beam parameters could be the same ones that generate the signals that shut the beam down in an off-normal event.

These issues should be quantified as they may affect facility design.

7. We recommend the ${ }^{3} \mathrm{He}$ target
and beam stop thermal analysis be
reviewed in detail.

Target backstop and beamstop designs presented to the review panel were not up to date. Significant re-design of backstop has been done since preparation of the descriptive documents and documentation of the thermal analyses was not available. Given the very high thermal loads on the backstop components and the possible production and safety consequences of cooling failure, we recommend the new design be reviewed.

\section{We recommend early development of an operations plan.}

Construction and operation of APT are likely to be carried out by a private vendor. It is important that the developers of the APT concept derive a plan for operation of the facility so that the contractor who has operational responsibility can plan for training and support. It is also important that details of the plan be part of the design process so that regular operation and maintenance can be simplified and made more reliable through proper design at the outset. Many design trade-offs have an impact on the availability and cost of actual facility operation and their impact should be understood early in the process.

Similarly, it is important to identify the operator of the APT facility. The operator will have a significant interest in the final design of the facility in terms of operational cost, safety issues, staff training, other applications, basic technologies chosen, etc. Early identification of the ultimate operator would facilitate an easier transition from design to construction to operation and ensure reliable production on schedule. 


\section{Appendices}

\section{A. Detailed recommendations on accelerator concept}

1. The $3 / 8$ goal design presented is adequate for production of the required quantities of tritium. There is potential for further design improvement leading to increased availability and cost reduction.

a) If the design is constrained by any fixed formula of "availability" where some beam current must be available during a fixed fraction of the year, this may lead to parameter choices that do not maximize production or minimize cost.

The design goal might be stated in terms of integrated beam power over the course of several years. Above a proton energy of $\sim 200 \mathrm{MeV}$, tritium production rises approximately linearly with beam power.

b) Even minor improvements in electrical efficiency should be given high priority in design parameter choices.

i) Operational expenses are dominated by electricity cost so that improvements in efficiency are very important. It appears that each $1 \%$ improvement in electrical efficiency reduces operating cost by at least $0.8 \%$.

ii) Significantly better efficiency can be realized by some simple optimization strategies during operation. The klystrons do not all have to be operated below saturation. In the planned arrangement of feeding one extended structure from six or seven amplifiers, only one or two of these amplifiers need be operated below saturation to provide voltage overhead for control. Also, slow variations in power needs (time constants about one second) can be easily obtained by varying the klystron voltage or the modulating anode voltage, and does not need to imply that the klystron is running at reduced efficiency. This sort of optimization strategy would appear to improve the nominal efficiency of the APT by about $10 \%$, pending more detailed studies of operating modes.

c) The RF system as specified in the Point Design has several features which do not represent common practice, and which we believe should be carefully reviewed and probably changed, including:

i) Wave guides might be split, using a hybrid coupler, to feed two accelerator cavity sections. In this way reflected power caused by a mismatch between the power provided, and the power transferred to the beam and the structure, can be absorbed in a load. The $\mathrm{RF}$ generator is protected in this way so that a circulator may not be required. A circulator may still be desirable, but the amount of power that it would be expected to absorb would be much reduced. Thus especially if the frequency choice remains at $700 \mathrm{MHz}$, the requirements on the circulator would be relaxed, reducing cost.

A second advantage of splitting the RF power in this way is that the shortened accelerator structures allow the use of the preferred focus-defocus (FODO) lattice ${ }^{37}$.

A further advantage is that the wave guide power is reduced to the point that there should be no special challenge in making a completely reliable $R F$ window.

ii) The accelerator structure could be fed from symmetric feeds, not all from one side. The transverse beam kick that results from asymmetric feeds is not desirable. Unless canceled in this way, the kick is likely to be beam current dependent since the flow of RF power into the structure depends on beam current. The split could be before or after the RF window; if before the window, then power through the window would be further reduced and would be far below levels commonly used. 
iii) Improving feed symmetry will reduce the forces that may increase beam halo. A reduction in halo provides a lower radiation environment near the accelerator and may provide greater reliability of components located in that area.

d) Recent developments, especially the work being done on $476 \mathrm{MHz}$ klystrons by SLAC and Varian, should be examined because they suggest much simpler and less costly approaches.

i) They avoid the complexities and potential resulting instabilities from the use of a "modulating anode" or mod anode as it is usually called. European designs from Thomson, Valvo, and Siemens use mod anodes to control beam current so that klystrons can be run near saturation for whatever power output is desired.

Difficulties occur when the high-impedance mod anode circuit encounters reflected electrons from high-field cavities.

ii) Instead of limiting the current with a mod anode, consider using a variable voltage power supply to set the klystron voltage level to supply only the needed power, plus some amount for needed overhead for fast feedback circuits.

iii) For larger amounts of reserve power, potentially including enough to compensate for a failed neighbor station or to provide power for an increase in the proton beam current, simply raise the dc voltage. If klystrons operate near optimum voltage, then the increase in output power scales as $\mathrm{V}^{5 / 2}$.

iv) Klystron lifetime will probably not be limiting. The klystrons are generally going to be operated in a very conservative way, so that long life should be assured. In addition, except for an occasional case where something simply breaks, klystrons do not suddenly wear out. For example, cathode failure can be seen long before it becomes a limitation by the need to increase cathode heater power to maintain required beam current. These components may then be replaced during regular maintenance periods. e) Recent advances in inductive output tube technology should be examined.

Potential advantages for a higher-ordermode inductive output tube include lower voltage for reduced component failure rates, higher efficiency over a wide power range, and reliable crowbar for fewer trips. A circulator will probably not be required. These advantages may improve availability and reduce cost.

f) The choice of frequencies should be reviewed along with development in power sources and accelerating structures.

The point-design choice of $700 \mathrm{MHz}$ results from the choice of $350 \mathrm{MHz}$ for the low energy part of the machine. The emittance from the $350 \mathrm{MHz}$ RFQ is a good match for the rest of the linac and the frequency is low enough to accommodate the requirement for $100 \mathrm{~mA}$ of beam current. The shunt impedance at $700 \mathrm{MHz}$ can be somewhat higher (about 10\%) than at about $500 \mathrm{MHz}$, resulting in somewhat better efficiency. This comparison assumes a fixed beam tube opening diameter.

It could be argued that if the klystron, for example, is less conservative at $700 \mathrm{MHz}$, one should use more conservatively designed 500 $\mathrm{MHz}$ tubes. On the other hand, a $700 \mathrm{MHz}$ linac has smaller components and certainly requires much less copper. The choice of frequency seems to be an issue that cannot be decided without the sort of point design studies suggested above.

g) Individually variable power supplies should be considered as an alternative to the large $A C-D C$ power supplies with indioidual conditioning boxes currently incorporated into the APT concept.

This selection affects the need for modulating anodes in the klystrons and their associated power supplies. Klystron power in the point design was specified as coming from very large dc power supplies, rated at $250 \mathrm{MW}$ and capable of running 100 tubes. This concept is not desirable for a number of reasons, including the cost of protection devices, the inflexibility of operating all tubes at the same voltage, various safety issues, and the difficulty of servicing a station while other neighbors are operating. In the PEP-II project at SLAC, it is planned to build individual SCR-controlled power supplies. The 
cost of these supplies including control, regulation, crow-bar, for an order of 11 supplies, is expected to be about $300 \mathrm{k} \$$ each for $90 \mathrm{kV}, 27 \mathrm{~A}$ ( 2.5 MW) supplies.

h) The point design includes provision for one spare klystron for every five that are on line in the low energy part of the CCL.

This is equivalent to a $20 \%$ reduction in efficiency in part of the linac. An alternative approach would be to run klystrons and structures below rated capabilities, as indeed seems to be the case, so that spare tubes in hot sockets are not needed. The complicated wave guide switches would be eliminated.

i) Realistic limits of beam deflections due to changes of loading, or other jitter-type problems, need to be established to assure that not too much beam pozver falls on one section of the target.

Beam transport to the target chambers requires expanding the beam to avoid overheating the windows. The design presented used nonlinear lenses (primarily octupoles) together with quadrupoles to provide control for the beam expansion. This system appears to have the flexibility needed to deal with the types of beams that will occur. For example, operating the expander with Gaussian beam profiles is probably not realistic, and can be considered a worst case.

2. We recommend that work on the low energy $C C L$ presented to us be continued. It could become the basis of the experimental Risk Reduction Program to test accelerator components.

The New Design Concepts for APT talk that was presented by J. Billen contained a number of desirable features including replacing the $350 \mathrm{MHz}$ low-energy part of the design with Coupled-Cavity Drift Tube Linac structures. The approach promises to be much improved over the earlier design. All focusing magnets would be outside the accelerator structure, and would be available for alignment and servicing. The entire linac could be made to use FODO focusing as suggested elsewhere.

3. Detailed experiments with the ion
source should be performed to perfect
its performance for the APT
requirements of current and emittance.

Examination of the proposed design and the characteristics of similar sources 52 indicate that the proposed ion source has a relatively small design margin for producing the required $100^{+}$ $\mathrm{mA}$ protons at the emittance required by the RFQ. We recommend consideration of an increase in the design margin.

An experimental design effort should be part of the risk reduction program to perfect the source optimized for APT. The program should be able to define the source's characteristic lifetime, maintenance cycles, failure modes, proton fraction and phase space distribution. Specific steps are suggested below.

a) The risk reduction program should include studies of ion source lifetime at full current to determine the causes of failure and identify limiting components.

It is important to identify source modifications that may extend useful lifetime. Whether or not the lifetime is found consistent with anticipated operating schedule can be determined and a means found to rapidly switch to a standby source if needed.

\section{b) The funnel design should be validated in the risk reduction program.}

The experiments could be done using a single beam with good diagnostics that observe emittance and phase space filled by the beam.

4. We recommend requirements be
developed for mechanical alignment
and power supply tolerances to
maintain adequate beam quality.

The requirements should be specified in development of the cost and schedule plans, and reasonable variations in beam spatial profile and current should be studied to determine the vulnerability of accelerator and target components to those variations. 
A plan should be developed for implementation of appropriate beam diagnostics . to monitor those variations during operation.

\section{Tunnel depth may be excessive and thus costly.}

The depth chosen for the main accelerator tunnel seems to be arbitrary. The present concept requires deep burial that precludes open pit construction and requires underground boring to construct the accelerator tunnel, an expensive choice. Reducing the tunnel depth to the point where open pit construction is appropriate would reduce the plant cost substantially. Above ground earthen berms should be considered as an alternative to deep burial. Cut and cover techniques are usually the least expensive way to achieve an accelerator tunnel.

It appears that the tunnel depth may have been determined by a rather improbable worst case accident scenario. As a result of this, preliminary calculations indicate that this leads to two orders of magnitude in the margin of safety. The $12 \mathrm{~m}$ earth shielding required for this scenario leads not only to increased civil construction costs but also to those for RF transmission lines, utilities, and cable runs.

As the reference design is
developed into a conceptual design, a
specific definition of the instruments
and control systems will assist in
development of the most reliable
design.

APT needs to have a controls philosophy defined so that subsystem designers know what is expected. To maximize the probability that subsystems will integrate into the APT overall controls structure, it needs to be defined. It is important that, as the designs progress, the expectations on interfaces and control functionality be understood and properly accounted for by the subsystems' designers.

\section{Beam trip conditions and recovery times need to be worked out.}

To evaluate the reliable tritium production the false alarm rate needs to be estimated along with the time that will be required to recover from a true or false alarm.

The natural convection-driven flow that is to be used to remove APT target residual heat following beam termination has a different character than the usual forced mixed-mode flow in which both free and forced convection heat transfer coefficients combine into a value that is governed by the hydraulics of the entire cooling loop and the heating surfaces. To evaluate the performance of the loop and to benchmark the thermal-hydraulics model of the loop we recommend using a code such as TRAC with experimental data for analysis. An example has been shown for the General Electric Test Reactor $^{38}$ (GETR), and this was needed as a starting point to determine more serious accident scenarios. 


\section{B. Detailed recommendations on production target concept}

1. Much of the predictive
uncertainty is in the modeling of
neutron generation and transport, and
tritium production in the target. These
uncertainties require engineering design
margins that increase facility cost.

Tritium production modeling can be used to gain cost savings and schedule improvements. Assessment of trade-offs, for example, in the areas of material and fabrication cost and production efficiency, can be done using validated predictive tools. The same tools can provide reliable, accurate modeling to respond to changing needs in the future with new designs. Examples of alternate designs include a W/Li target system, a lower current machine running at higher beam energy (e.g. $2 \mathrm{GeV}$ ), or a deuteron or alpha beam machine.

Optimization of the operating schedule is another area that can benefit from accurate predictive tools. For example, the best response to the failure of some number of RF sources can be determined based the effect on the production rate of a decreased proton beam energy.

Numerical computer experiments can be executed without the costs that an experiment will incur.

We recommend the following:

a) Modeling of the neutron production, transport, and tritium production processes should be reviewed in detail by knowledgeable experts and improved.

The success of APT depends on meeting the production goal. A crucial tool used in the design of the accelerator and target subsystem is the suite of neutron production and transport codes. The predictive codes appear to have been used correctly and the data bases used are the best available. Nevertheless, the calculations should continue to be reviewed for improvements.

In the calculations of the initial neutron generation and high energy transport, choices among physics models must be made. The sensitivity of tritium production to these choices should be explored. If the production prediction does not depend strongly on these choices then a higher confidence in the prediction is warranted.
The calculations predicting the tritium production per proton are tedious and difficult to prepare. At this point they have not been independently reviewed, but should be. For example, using a material composition that does not include a component whose cross section is large may lead to errors even if its abundance is small.

b) It is important that reliable uncertainty estimates for the tritium production rate be developed and reassessed as appropriate and reduced to the extent possible.

The estimate of the uncertainty in the tritium production directly corresponds to a contingency that must be allowed for in the accelerator and target designs. At present this uncertainty is not known. The calculations that have been done to this point have used the LAHET Code System (LCS) the major components of which are LAHET (for spallation and high energy particle transport), MCNP (for lower energy neutron and photon transport) and CINDER90 (for radio nuclide production and decay). LCS has been applied to a limited set of benchmark experiments in the relevant energy range, none of which capture all the important aspects of APT. In the Sunnyside ${ }^{30}$ experiments, in which total neutron production was measured by a $\mathrm{Mn}$ water bath activation method in a highly moderated system, the calculations and experiments agree well, at the $\sim 5 \%$ level. In another set of experiments $27,29,32,35$ on physically smaller assemblies the measured and calculated neutron-per-proton values were discrepant by $-15-20 \%$. In these experiments the calculations consistently over predicted the neutron yield. At this stage we do not know where APT lies between these two sets of experiments. We feel confident that the tritiumper-proton is known with an uncertainty that is smaller than $20 \%$.

A direct evaluation of the uncertainty in the predicted $\mathrm{T} / \mathrm{p}$ from the raw data that go into the data bases and the physics models that the codes use is impractical. There are alternate, less direct ways to assess the model uncertainties. One method is inter-code comparisons. We 
suggest that the physics models and their effects in LAHET be evaluated. Comparisons between LAHET run at LANL and BNL could be done. Also comparisons to the French code, TIRCE, should be undertaken. In addition comparisons of calculations done using different cross section data bases (e.g. ENDL and ENDF/B) should be done.

A second approach to an assessment of the uncertainties in the calculated $T / P$ is through sensitivity studies. In such an approach a variety of parameters in the calculations would be changed and the sensitivity of the result to such variations examined. In this way contributions to the uncertainty can be ranked. For example, the elemental composition of some component of the target assembly could be varied slightly. If the resulting $T / p$ did not change then one can be confident that the details of the composition of the varied component are not an important contributor to the calculational uncertainty. The sensitivity to the inputs and outputs of the different stages of the LCS should be examined and the most critical components identified.

Once sensitivity studies have been done, the possible improvements in the codes and data bases that would tighten the uncertainty bound could be prioritized. Such improvements include parts of the physics models in LAHET and extensions of the cross section data bases to higher energies and improvements in the cross sections for the most important isotopes. We recommend that a group of people be assembled and given a charge to look into the adequacy and improvements in the physics models and data bases concerning APT T/p calculations.

\section{c) Evaluate spallation products that may introduce parasitic neutron capture.}

Further nuclear data evaluation should be done to establish the impact of spallation products on parasitic neutron capture. Preliminary calculations have been done by $W$. Wilson (LANL) using the CINDA code to determine the impact of such processes on tritium production. Further work should be done to assess neutron capture cross sections on spallation products, and how this effects the time dependence of tritium production.

2. Tritium production experiments
are an important part of the risk
reduction program and should be
reviewed in detail to insure they are
well planned and focus on specific
questions relevant to facility
performance.

A series of experiments consisting of basic tests to benchmark the predictive tools, and realistic simulations to empirically validate designs will reduce the schedule risk and improve the availability of tritium production in goal amounts. Experiments can include multiple but simple diagnostic tools that can be calibrated during benchmark tests and later used in realistic simulations to explore the details of target performance. These tools will be especially useful if results are at variance with predictions.

Specific issues to be studied include the spatial distribution of high energy neutrons in the assembly, their energy spectrum, and the spatial distribution of thermal neutrons. Tritium production efficiency and its loss mechanisms within the assembly can be understood as well during the risk reduction program. Finally, tritium production and extraction must be demonstrated quantitatively to provide confidence in the predictive tools.

\section{a) Deuterium would be the best tritium tracer, but there are many problems.}

Tritium can be lost by absorption into target and structural surfaces. Hydrogen (and its isotopes) is known to be highly reactive with metal surfaces and with liquid films to which it may be exposed. Tritium processing is generally accompanied by early losses as the surfaces are saturated where the extraction rate is considerably less than the production rate. Then the extraction rate equilibrates to a value close to the production rate as surface equilibrium is reached.

Experimental tests of the APT target/blanket assembly will generally be done at very low tritium production rates where equilibrium may be established over a very long time, possibly much longer than the test duration.

Consequently, tritium reactions with surfaces in the assembly may fundamentally alter the extraction rate and make test results difficult to interpret. 
Saturation of target/blanket assembly surfaces with deuterium provides a means of saturating the surfaces with larger masses of hydrogen without the safety concerns of tritium handling or high level neutron irradiation. Deuterium provides a mechanism for study of surface effects using a gas species distinct from the normal background gases, but whose chemistry is nominally the same is the tritium of interest.

However, deuterium gas is already chemically combined and there may be some chemical differences between its surface reactions and those of atomic tritium. Differences in chemistry must be understood if deuterium is to be used to study the movement of tritium in the processing system.

\section{b) Tritium production capsules can be} developed for the risk reduction plan.

Small capsules with specially prepared surfaces and containing ${ }^{3} \mathrm{He}$ at the nominal APT blanket pressure could be placed in the simulated APT target/blanket assembly to measure the tritium production rate. They could have trace amounts of deuterium (possibly with an inert tracer inserted into the assembly). Subsequent removal of the capsules followed by sensitive mass spectrometry obviates the tritium losses in the extraction loop and provides data on the spatial distribution of tritium production. Methods would need to be adapted or developed to insure total tritium recovery. This type of method would provide an overall benchmark for calculation and models and provide the hardest numbers on $\mathrm{T} / \mathrm{p}$.

c) Several noble gas isotopes would be useful in the study of neutron fluxes in the target assembly.

A short list is given below with the respective reactions, neutron cross section, and lifetime of species formed:

$$
\begin{aligned}
& { }^{40} \mathrm{Ar}(\mathrm{n}, \gamma)^{41} \mathrm{Ar}, \mathrm{T}_{1 / 2}=1.8 \mathrm{hr}, \sigma=1 \mathrm{~b} \\
& { }^{78} \mathrm{Kr}(\mathrm{n}, \gamma){ }^{79} \mathrm{Kr}, \mathrm{T}_{1 / 2}=35 \mathrm{hr}, \sigma=20 \mathrm{~b} \\
& { }^{78} \mathrm{Kr}(\mathrm{n}, 2 \mathrm{n})^{77} \mathrm{Kr}, \mathrm{T}_{1 / 2}=1.2 \mathrm{hr} \\
& { }^{78} \mathrm{Kr}(\mathrm{n}, 3 \mathrm{n})^{76} \mathrm{Kr}, \mathrm{T}_{1 / 2}=14.8 \mathrm{hr} \\
& { }^{124} \mathrm{Xe}(\mathrm{n}, \gamma){ }^{125} \mathrm{Xe}, \mathrm{T}_{1 / 2}=17.1 \mathrm{hr}, \sigma=600 \mathrm{~b} \\
& { }^{124} \mathrm{Xe}(\mathrm{n}, 2 \mathrm{n}){ }^{123} \mathrm{Xe}, \mathrm{T}_{1 / 2}=2.0 \mathrm{hr}
\end{aligned}
$$

$$
\begin{aligned}
& { }^{124} \mathrm{Xe}(\mathrm{n}, 3 \mathrm{n})^{122} \mathrm{Xe}, \mathrm{T}_{1 / 2}=20 \mathrm{hr} \\
& { }^{124} \mathrm{Xe}(\mathrm{n}, 4 \mathrm{n})^{121} \mathrm{Xe}, \mathrm{T}_{1 / 2}=39 \mathrm{~m} \\
& { }^{124} \mathrm{Xe}(\mathrm{n}, 5 \mathrm{n})^{120} \mathrm{Xe}, \mathrm{T}_{1 / 2}=40 \mathrm{~m}
\end{aligned}
$$

The noble gas tracers described above could be introduced into the circulating ${ }^{3} \mathrm{He}$ as a diagnostic tool. Collection of $\mathrm{Br}$ and $\mathrm{I}$ radioactive decay products would then provide neutron dosimetry in the target assembly. The decay products could readily be analyzed by $\gamma$-ray spectroscopy.

These species provide additional information to interpret tritium production experiments since their reaction products may be more easily extracted than tritium. Some of them are less chemically reactive or can be rapidly combined with a carrier gas due to their lower kinetic energy so that losses on the surfaces of the APT target/blanket assembly may be less important, better understood, and equilibrium reached more readily.

\section{d) Other neutron diagnostics could be} developed for the risk reduction plan. Types of diagnostics that should be evaluated include:

\section{i) $(n, x n)$ reactions}

The higher energy parts of the neutron flux spectrum could be tested using reactions such as $(n, 2 n),(n, 3 n), \ldots(n, 7 n)$ on Lu, Eu, Ir, or $\mathrm{Tb}$. These reactions have thresholds at various neutron energies, from about $2 \mathrm{MeV}$ to as high as about $100 \mathrm{MeV}$.

ii) $\mathrm{Gd}(\mathrm{n}, \gamma)$ reactions.

Gd samples could be arranged within a production test assembly to yield data that could be used to understand the spatial dependence of the low energy part of the neutron flux.

\section{iii) fission track detectors}

Fission track detectors using lower A fission foils could have quite high fission thresholds that would probe the higher energy parts of the neutron flux. Track detectors may have the advantages of high sensitivity and high signal to noise. 
e) Tritium chemical interactions and binding should be investigated in the risk reduction plan.

After irradiation of the production test assembly the parts should be inventoried for tritium to identify parts that might absorb tritium. This would elucidate chemical effects relevant to recovery of tritium from a working target/blanket assembly.

3. Consistency between engineering
and neutronics calculations needs to be
improved.

Consistency of target modeling and target designs should be checked on a continuing basis to insure that all materials and components proposed for the designs are validated in the production modeling of the target. The exact elemental composition of the materials that make up the target/blanket must be given as input to the tritium creation calculations. In order for the calculations to predict correctly the actual creation of tritium the compositions used must accurately reflect the materials that are used in construction. For example, the lead parts of the blanket of the ${ }^{3}$ He target were modeled as pure lead.

Pure lead has a low thermal neutron absorption cross-section, making it a desirable material from the neutron economy point of view. However it is difficult to produce machined parts to even moderately tight tolerances from pure lead. Therefore, in many components of other systems, the material that is called lead is an alloy of lead and other metals (typically antimony or arsenic). If such an alloyed form of lead is required for engineering performance the tritium creation calculations must take this into account.

In addition, pure lead is a soft material that is subject to creep over time, an effect that is worse at elevated temperatures. If the creep is sufficiently bad the parts of the blanket that are intended to be recycled may not be reusable. In the worst case this would mean that each target would have to be built with new lead or with reprocessed lead from an earlier target.

A third area of concern regarding lead (or its alloys) is that it could be subject to corrosion under some chemical conditions of the coolant. Any such corrosion could limit the useful life of a target assembly as well as contaminating other parts of the coolant circuit.

The neutronic properties of a lead alloy are different from that of pure lead. The neutronic model of the target/blanket must account for the materials that will be need to be used to satisfy the engineering requirements of the system. The consistency between the tritium production calculations and the target/blanket engineering requirements should be reviewed.

4. Beginning with the conceptual
design phase the target/blanket system
should be designed with component
lifetime and plant life cycle costs in
mind.

The target/blanket lifetime, actual and expected, will have substantial impacts on the operations and operating cost of APT. If a target fails or becomes unusable tritium production could be disrupted. On the other hand taking a target out of service before it is necessary increases costs and waste disposal requirements.

a) Target designs need to address the buildup of hydrogen and helium gas in the solid components.

During operation of the APT system gas will build up in the solid components of the target ( $3 \mathrm{He}$ or SILC). Gas trapped in target components can substantially degrade the mechanical properties of materials (e.g. causing embrittlement and swelling). For either target system protons and neutrons that stop in the target will contribute to the buildup of hydrogen gas. In addition spallation products will build up in target components as well. These products will include hydrogen and helium.

For the SILC target design the effects of gas buildup can be addressed by examining the operating experience with the similar production operation at the Savannah River plant. New features in the APT plant will be the high energy proton beam with its effects and the implantation of recoiling coolant atoms into the cladding material.

In the ${ }^{3} \mathrm{He}$ target system the main mass of the target that is exposed to the direct proton beam is subject to minimal mechanical stress so 
that embrittlement should not cause problems. The method that is used to hold the tungsten rods allows for longitudinal and radial swelling of the rods so that dimensional changes also should not be a problem. The lead blanket will also be subject to high energy particle flux that will cause spallation. The effects of gas generation must be assessed, especially for those parts of the lead blanket that are expected to be re-used. Note that these parts have alignment holes and coolant flow channels with dimensional tolerances. In addition these parts are sufficiently massive that there will be substantial stresses on them.

The effect of gas buildup in the target/blanket components needs to be assessed. Methods for this assessment include examination of relevant nuclear reactor experience, numerical modeling and experimental testing at LANSCE or other suitable accelerator facilities.

\section{b) Spallation product buildup in the target coolant should be studied for possible safety and/or technical risks.}

Under the flux of high energy protons and neutrons that will exist in the target/blanket area, nuclei of the components will undergo spallation. The spallation products will be created with high energy and some fraction of them will escape into the coolant. Most of the spallation products will be radioactive. The effects of the activity and chemistry of these spallation products in the coolant must be assessed. Safety risks include release of radioactive coolant. Possible technical risks include the possible chemical interactions of the spallation products with the coolant handling system and activation of parts that will require maintenance. The risks need to be assessed and appropriate mitigation planned.

\section{c) Spallation product buildup in the target should be studied for the effects on neutron economy.}

Further nuclear data evaluation should be done to establish the impact of spallation products on parasitic neutron capture. Preliminary calculations have been done by $W$. Wilson (LANL) using the CINDA code to determine the impact of such processes on tritium production. Further work should be done to assess neutron capture cross sections on spallation products, and how this effects the time dependence of tritium production.

d) The effects of coolant radiolysis products in the radiation environment should be considered in target design.

When water is subject to radiation (specifically charged particle flux) it is broken down by radiolysis forming highly reactive chemical radicals and other neutral and ionic species. All of these species can be extremely corrosive. The effect of radiolysis on the components of the target/blanket cooling system should be assessed. This concern can be partly addressed by comparing the expected ionization density in the APT coolant with that in a nuclear reactor and with the LANSCE target. In addition a comparison could be made between the radical production rate and mean lifetime. Since the radicals are expected to have short lifetimes a relevant experimental test requires careful design. In addition to direct effects on the target parts the radiolysis induced changes in the coolant chemistry could have deleterious effects on other parts of the coolant handling system.

e) A materials surveillance program aimed at extending the operating life of components and reducing costs should be planned and implemented before routine operation begins.

The chemical state of the tritium
needs to be considered in the design.

In the ${ }^{3} \mathrm{He}$ target system most of the tritium will be created as an ion with about 200 $\mathrm{keV}$ of kinetic energy. The range in helium of such an ion is $\sim 165 \mu$. Tritium ions that are created within approximately this distance from the walls will have a chance of implanting into the walls and not being extractable. This tritium (and the hydrogen that is created along with it) will alter the mechanical properties of the materials into which it implants which could affect the useful life of the target/blanket assembly.

It is known that hydrogen has a high chemical affinity with a wide range of different materials. If such materials are exposed to the gas stream in the ${ }^{3} \mathrm{He}$ target system the tritium will become chemically bound and thus not be recovered in normal operations. The potential of 
this effect to reduce annual tritium production should be addressed quantitatively. If tritium binding is a significant effect possible prevention methods, such as passivation of surfaces, presaturation and normal hydrogen flushing should be explored.

6. Thermal-hydraulic tests relevant
to the target rod bundles, the target
backstop and tuning beam stop need to
be designed and conducted.

Thermal-hydraulic design in all watercooled target passageways including those of the complex multiple, parallel flow coolant passages in the beam backstop is critical to avoid burnout caused by bulk boiling or Departure from Nucleate Boiling Ratio (DNBR). Experiments to validate the adequacy of the passage sizing and design are essential.

The thermal-hydraulics design of the target is crucial to avoid burnout resulting in costly re-design. This is especially important owing to the difficulties in implementing adequate testing diagnostics within the target.

The largest uncertainty in the target thermal-hydraulics is the critical heat flux (CHF). Acquisition of a CHF design data base correlation for each water-cooled target component is recommended and should consider geometric, heating, and fluid flow dependencies including heating length, hydraulic diameter, pressure, velocity, sub cooling, and passageway peripheral heating profile and shape (aspect).

\section{Watson ${ }^{39}$ shows existing CHF}

correlations for use on plasma-facing ITER components vary by as much as $5 / 1$ from oneanother at the same mass flow flux. In addition to this uncertainty, Celata and Cumo ${ }^{40}$ conclude that a high heat flux for fusion reactor technology requirements, the burnout mechanisms understood for thermal-hydraulics of watercooled fission reactors show completely different physical aspects. For applications 40 , the experimental acquisition of a CHF design data base correlation for each water-cooled component was recommended.

Dependencies of $\mathrm{CHF}$ on passageway configurations was noted by Zeigarnik ${ }^{41}$ for nearly square channels in which the $\mathrm{CHF}$ with just one side heated was nearly equivalent to that for the uniform peripheral heating of a tube having the same hydraulic diameter. Landram ${ }^{42}$ has investigated burnout in high aspect ratio parallel channels separated by thermally conducting walls, somewhat similar to the emerging slotted passageways of the backstop and other water-cooled APT components, and found that burnout was caused by dryout of the saturated channel region near the heated end even though the remainder of the coolant in the flow cross-section was sub cooled. Experiments and analysis were essential in providing confidence for design that cannot always be tested under prototypical conditions.

Additionally, an experimental validation of the energy deposition rates for the various water-cooled target materials should be produced, and an uncertainty analysis based on these results and those on CHF correlations should be performed so that reasonable conservatism in DNBR for the emerging designs can be demonstrated. This analysis should include at least a two-dimensional assessment of the heat flux distribution around the periphery of the cooling channel within its flow cross-section.

An experimental simulation of a segment of the beam stop should be considered by electrically heating the closely packed rods of a prototypical plate (with heated adjacent surfaces).

Both the local radiative view factor between the center of the rods and the watercooled vessel as well as axial heat conduction within the rods are extremely weak heat rejection mechanisms that will likely result in rod damage. A linked-code system, such as the LLNL MONTE ${ }^{43}$-TOPAZ ${ }^{44}-$ NIKE $^{45}$, should be enlisted for computing the radiative exchange factors which couple to radiative-conduction exchange and thermal stress in the rods. This system of codes has been used to design the U-AVLIS separator at LLNL.

The linked system of codes predicting the thermal-stress analysis (e.g., MONTE-TOPAZNIKE) could also be used to design and analyze a scaled-down experiment, providing validation of code application to the prototype design. 


\section{Detailed recommendations on risk and availability}

The conclusions and earlier recommendations indicate that no major technical obstacles remain to the successful construction and operation of an APT facility. Nevertheless, the point designs presented may not be optimum for the most economical production of tritium. There are a number of issues remaining that could effect the cost of the APT facility and that could effect the risk that the schedule might not be met. The recommendation of the assessment team is that the "risk reduction program" should focus on cost reduction and issues that involve risk to the operating schedule. We recommend that the potential impact on availability and schedule of each facility component be ranked and that the risk reduction program be configured with that priority in mind.

\section{Experiments on LAMPF should be given high priority in LAMPF scheduling to ensure their timely completion.}

The conceptual design of APT depends on results of the risk reduction program, including experimental validation of design choices. Timely completion of the design process before procurement requires that experimental validations not be delayed. High priority access to the LAMPF facility may be required for timely completion of the experimental portion of the risk reduction program.

2. Accelerator components should
be assembled into a prototyping facility
as they are developed during the
technology demonstration process.

The key system components should be assembled as an operating accelerator to the extent necessary to prove component performance. The idea presented during the review of using the Ground Test Accelerator (GTA) tunnel facility to assemble ion source, beam transport, RFQ, funnel and follow-on accelerator components is consistent with this recommendation. Using this technique to prove and perfect the components would minimize the systemic technical risks while providing a proper integrated testing environment.

\section{Equipment reliability will be improved by proper consideration of radiation levels during facility design.}

We recommend the following:

a) We found the $3 / 8$ and $3 / 16$ concepts designed with appropriate conservatism concerning beam loss and avoidance of accelerator activation. We nevertheless recommend continued study of the physics of beam halos. be addressed:

In particular, the following areas should

i) There were several changes in the focusing lattice through the length of the linac. To the maximum extent possible, efforts should be made to minimize the number of transitions and beam matching sections since these are the principal sources of beam scrape-off.

ii) The focusing lattice should also minimize actions that cause the charge density of the beam to change, because this action can act as a pump for creating beam halo. The lattice should be changed from doublets to alternating singlets, or in the jargon, from FDO to FODO, to minimize changes in beam cross section area. Note that the "New Design Concepts" presentation ${ }^{37}$ referred to above would permit such a uniform lattice.

b) A definition of beam diagnostics to sense important variations in beam spatial profile should be developed.

The definition and analysis of required beam diagnostics needs to be accomplished with a view toward day-to-day operating needs.

c) Studies of beam pointing stability and control during acceleration should be continued. 
Improvement in stability and point accuracy reduces scrape-off that increases personnel risk during hands-on maintenance and technical risk to target and window materials.

4. Proper selection and monitoring
of materials used to fabricate accelerator
and target components will have a major
impact on facility availability and
annual production rate.

We recommend the following steps to search for improvements to the existing point design:

a) Target designs need to address the buildup of hydrogen and helium gas in the solid components.

The need for this assessment has been discussed earlier in the target/blanket section, Appendix B, section 4(a).

b) Spallation product buildup in the target coolant should be studied for possible safety and/or technical risks.

The need for this analysis has been discussed earlier in the target/blanket segment, Appendix B, section 4(b).

Experience on LAMPF indicates that no detectable tungsten isotopes are found in the coolant, but the composition of that target includes copper binder and is different from the APT design. Possible technical risks include the possible chemical interactions of the spallation products with the coolant handling system and activation of parts that will require maintenance. The risks must be assessed and appropriate mitigation planed for.

c) The effects of coolant radiolysis products in the radiation environment should be considered in target design.

The need for this consideration has been discussed earlier in Appendix B, section 4(d)

d) Reasonable variations in beam spatial profile and current should be studied to determine the vulnerability of accelerator and target components to those variations.
The results of the study can be used to help define the requirements for beam diagnostics and monitoring systems for the accelerator and predict stress points on the target.

5. If the Risk Assessment and
Maintainability (RAM) analysis is going
to be used to estimate availability, it
should identify sensitive components
and subsequently assign requirements
of availability for subsystems. The
RAM analysis also needs to be upgraded
to accommodate the operation of APT
production with degraded components.
Statistics based reliability simulations
should also be used in the analysis.

Modern industrial methods can be employed to assess, quantitatively, technical risks and incorporate the results into the designs. Risk assessments can be used to help prioritize the elements of the risk reduction program. The binary nature of the present RAM analysis may lead to erroneous conclusions. It does not appear to have any mechanism for accommodating statistical distributions of component failures.

The RAM preliminary study was based on a fault-tree rather than reliability methodology. While the former approach is satisfactory for scoping the problem and establishing the availability goal for the current design, the latter method is recommended for addressing availability issues in the long term.

Specifically, the following tasks are recommended: establish APT specific equipment database, allocate reliability goals, use Markov process for repair schemes, establish testing program to determine failure distributions and to specify reliability, establish equipment failure and repair reporting, evaluate availability improvement scenarios (redundancy, graceful degradation), establish condition monitoring and preventive maintenance program, establish repair work station resources (manpower and spares), and provide input to the optimization of life cycle costs.

The reliability data used in the calculations presented to the LLNL assessment team were based on the nuclear reactor equipment and other generic information. APT specific database needs to be developed. 
The definition of "success" needs to acknowledge that APT can continue to produce tritium, even at full rate, when various components fail. In reality, APT can continue to operate with many failed or degraded components. Even the failure of an RF driver (in the some locations) can be compensated for allowing APT to continue its mission in a degraded mode. There are relatively few failures (compared to the total number of components) that will completely stop APT's ability to produce tritium.

\section{A definition of the intended operation of the facility should be developed.}

Operation of the APT facility must be reliable and cost efficient. The details of that definition may have important consequences in facility and accelerator design. Operating a production plant is considerably different from operating an experimental research facility. This fact needs to be acknowledged and the required features documented. The impact will be felt on system architecture choices, degree of automation installed, and numerous other design choices.

a) A plan should be developed for operation of APT under conditions of a single component failure.

The plan should include provision for smaller lumps of RF power at the front-end and the use of the spare source concept.

7. Personnel safety in the facility during operation and maintenance will be improved by proper consideration of safety during facility design.

We recommend the following actions to improve personnel safety:

a) Design measures which reduce beam scrape off, discussed earlier, should be considered a personnel safety issue and managed accordingly.

Beam halo has been discussed earlier in the context of equipment failures caused by radiation damage. Radioactivation of accelerator components will also effect hazards to personnel conducting maintenance. The ability to carry out maintenance hands-on rather than using remote manipulators will greatly improve the functioning of the APT facility and reduce operations cost.

b) ESEH issues such as air actioation, radiation fields, shield design, staff dosimetry, anti-contamination control, accident mitigation and/or response should be integral to the design process. Inclusion of safety expertise in the design team would further this integration.

Radioactivation is currently being studied at SNL and estimates are being prepared for designs as they evolve. This activity should be continued and should be closely coupled with the evolving accelerator design.

c) Design changes, such as a downward bend in the beam line, should be considered for the SILC target so that the entire target area could be immersed in a water bath that would be less vulnerable to loss through a ruptured window. Consequences of a ruptured window should be addressed.

d) We strongly urge that a fundamental protection philosophy be developed early on and that ESEH planning be a substantial, integrated part of the design process.

Protective systems that are incorporated in later design stages as "add-ons" are quite likely to be more costly and less effective than systems that are developed along with the basic design of the plant. ES\&H analysis should also be an explicit part of the on-going assessment of plant operations. 


\section{Detailed analysis of cost \& schedule}

Considering the preliminary nature of the pre-conceptual design, the LANL/Bechtel team has prepared a comprehensive cost/schedule report; however, some project costs appear to have been overestimated, and the funding profiles and schedule need coordination and optimization. Several design recommendations made earlier (e.g., the SRF linac option) and those discussed subsequently should result in lower total project costs and better connectivity between the risk reduction program, funding scenarios and project milestones.

\section{Estimates of the Total Project Cost (TPC) should be reduced.}

a) The annual escalation rate of $4.5 \%$ is too high.

Large projects proposed under DOE sponsorship require an estimate of Total Project Cost (TPC) that includes many cost elements. TPC includes design and construction elements that are funded with capital money such as Plant and Capital Cost (PACE) while other elements of the same project, such as activation and startup are funded with operating money such as Other Project Costs (OPC). OPC should not be confused with Annual Operating Cost (OPEX).

Cost estimates are prepared according to DOE Order 5700.2D, COST ESTIMATING, ANALYSIS, AND STANDARDIZATION, dated 6-12-1992. Attachment 2 of this order specifies that Inflation (or Economic Escalation) must be included in the estimate. It states "All construction projects will be estimated in constant-year dollars in the year in which costs will be incurred and each year's cost will then be escalated using an appropriate escalation index."

DOE issues ANTICIPATED ECONOMIC ESCALATION RATES for DOE construction projects, annually, in January and publishes an update each summer. The January 1995 Guidance for Defense Programs \& General Construction covers the period from FY94 until FY00 giving the FY94 to FY95 rate as $2.6 \%$ and all subsequent years as 3.0 to $3.1 \%$. Use of these rates is appropriate to projects such as APT. b) A very high safety margin for linac shielding will lead to increased costs.

It was indicated that the response time for fast protection was less that $7 \mu$ s. Yet the "worst case" accident is 1 hour of "full" beam loss. That is $200 \mathrm{MW}$ of beam power striking the side of the linac. As a result of this worst case accident and "two orders of magnitude" of margin in shielding attenuation, 12 meters of earth shield is required. This has a major impact on the costs. The accelerator tunnel and beam transport cost is about $\$ 71 \mathrm{M}$. The other costs that are driven up by this are the RF transmission lines, utilities, and cable runs. A realistic analysis of a credible accident and resulting activation should be completed. The shielding should be designed to meet current standards, not with two orders of magnitude of safety.

c) The contingencies in the estimated TPC are expected to be reduced as the project proceeds into a conceptual design.

The contingency appears as the total for capital costs and ranges from $37-47 \%$ for different confidence levels (or $32 \%$ of cost when risk reduction is included). These estimates, obtained from the Bechtel Microrac model, should be evaluated further to understand the impact of different components and cost elements. On a straight percentage basis, these numbers seem to be in the right range for a pre-conceptual design and we find no basis for reducing them. They would be considered high for accelerator equipment, the largest cost element, at the conceptual design stage. Also, with the risk reduction program identifying key areas of concern, there should be a better handle on contingency management.

2. Impact of startup and operating
activities on cost and schedule should be
assessed.

a) Bechtel's estimated cost of power during the last quarter-year of startup (fourth quarter, 2007 ) is low at an annual rate of $\$ 40 M$. 
For 2008, the first year of full operation, they estimate power cost at $\$ 181 \mathrm{M}$. The rate of power consumption at the end of startup should be the same as the steady-state running rate, therefore, the $\$ 40 \mathrm{M}$ estimate appears to be significantly understated.

b) For the operating scenario that the plant will be in production for five-year periods and turned-off for the next five years, an electrical power demand charge will be applicable during the non-operating period.

Bechtel should verify if this cost will be incurred and add it accordingly.

\section{Several schedule related project funding issues and the impact of a compressed schedule should be evaluated.}

The discussions with the LANL/Bechtel team indicated that DOE had dictated the funding profile and schedule. A critical path schedule is required for the project as planned and for an optimized plan that reduces the overall cost and schedule.

a) There is too close of a coupling between the granting of KD1 and the beginning of the project; about 6-12 additional months should be allowed for the Congressional funding process.

Otherwise, there could be a funding gap between KD1 and Title I. To be able to submit an accurate project data sheet, the conceptual design and cost estimate needs to be complete. In this schedule, the costs and schedule is estimated midway in the conceptual design cycle. Are these estimates acceptable for the budget planners in DOE and the OMB? Using the funding history of NIF as a guide, the budget cycle started at the completion of the conceptual design roughly 18 months before Title 1. A solution to this problem is complete the conceptual design earlier and at lower cost.

b) Impact on cost and schedule of APT's current approach to have beam-centerline assemblies brazed by commercial sources should be studied.
This involves five or six successive braze cycles of diminishing temperature in a dry hydrogen retort, for each assembly. Given the number of assemblies, 342, and the number of cycles, this represents an enormous workload for the few possible commercial sources. At best, this represents tremendous risk in both cost and schedule performance. The development of a risk reduction strategy is strongly advised.

c) Further clarification about how LANL plans to provide accelerator windows, three port couplers and RF loads is needed.

The design, evaluation and fabrication of this class of microwave components is a difficult task at best, with few commercial sources. Here again, the risks to both cost and schedule should be of major concern.

d) There is no reference to a Management Information System (MIS) and the project needs a Management Plan as well as a Method of Accomplishment document.

This is a very important system to implement for tracking and controlling project costs.

4. Impact of RAM analysis on cost and schedule should be assessed.

The RAM analysis and the cost/schedule analysis should be an integrated activity. RAM analysis has a significant impact on cost and schedule estimates for the project by providing the model of the equipment requirements (Capital Cost) to meet not only the reliability and availability goals but also the personnel, repair station requirements and spare equipment (Operating Cost) necessary to maintain the systems at these goals for the life of the project.

During the risk reduction program, reliability growth estimates are used to estimate the time required to meet project goals and provide visibility on targeting areas for increased effort to meet these goals on schedule. RAM analysis is an effective tool for the evaluation of proposed changes in design by allowing comparison of the reliability growth of the system with the growth in capital cost and any decrease in operating cost realized by the change. 


\section{Estimates for several cost elements are within acceptable guidelines (as percentages) for similar projects.}

a) Engineering Design Inspection and Administration (EDIA) is stated to be \$440M including Title I, II, and II, and project management.

Calculating EDIA as a fraction of construction and fabrication cost, estimated at $\$ 1468 \mathrm{M}$, is approximately $30 \%$. This is within the range $15-35 \%$ considered standard practice, where the higher end corresponds to the most complex projects.

b) The estimate of the APT cost for A/E Title I \& II design work is $12.1 \%$ of the constructed cost of the Balance of Plant.
This compares favorably with U-AVLIS CDR costs at $14.6-16 \%$ and NIF at $10 \%$. Since NIF is a more environmentally benign facility, that probably accounts for its lower cost.

c) Instrumentation and Controls (I \& C) costs (exclusive of engineering) are estimated at $\$ 92.2 M$ out of a constructed cost of $\$ 1.593 \mathbf{M}$, or $5.8 \%$.

Comparable costs for NIF are $2.2 \%$ and for U-AVLIS plant scenarios range from about 3\% to $7.2 \%$, where the higher percentage corresponds to a smaller, scaled-down plant. APT at $5.8 \%$ is at the high end of being reasonable, in view of these comparisons. 


\section{E. Organization of the assessment}

The LLNL APT assessment team was organized into four committees. There was an Executive Committee to oversee progress and establish fruitful directions, an Accelerator Committee to review details of the accelerator design, a Target Committee evaluate details of the production targets, and a Cost and Schedule Committee to study the estimated cost, proposed schedule, risk analysis, and safety issues. Membership and affiliation of the committees is given below with $\left(^{*}\right)$ denoting chairmen:

\section{Executive Committee}

Tony Chargin, Energy

Frank Dietrich, Physics \& Space Technology, N-Div. Mike Kreisler, Physics \& Space Technology, N-Div. Wayne Shotts, Defense \& Nuclear Technology *Dennis Slaughter, Physics \& Space Technology, N-Div. Paul Wheeler, Defense \& Nuclear Technology, A-Div.

Accelerator Committee

John Barnard, Inertial Confinement Fusion

Rex Booth, Kaiser Engineers

Malcolm Caplan, Magnetic Fusion Energy

Andy Faltens, Lawrence Berkeley Laboratory

Bill Herrmannsfeldt, Stanford Linear Accelerator Center
Joe Kimbrough, Engineering Research, Elec. Eng. "Tom Moore, Computation \& Communications, Elec. Eng. Mike Moran, Physics \& Space Technology, N-Div.

\section{Target Committee}

Mark Chadwick, Physics \& Space Technology, N-Div. Jim Ferguson, Defense \& Nuclear Technology, B-Div. Jim Hall, Physics \& Space Technology, N-Div.

J.D. Lee, Energy, Mech. Eng.

Charles Landram, Mechanical Engineering Clint Logan, Engineering Sciences, Mech. Eng.

Winifred Parker, Physics \& Space Technology, N-Div.

*Ken Sale, Physics \& Space Technology, N-Div.

Joe Sefcik, Defense \& Nuclear Technology, A-Div.

Mark Mintz, Defense \& Nuclear Technology

Victor Karpenko, Energy Systems Engineering, Mech. Eng.

\section{Cost \& Schedule, RAM, ES\&H Committee}

Peter Alesso, Applied Research Engineering, Mech Eng Ed Greybeck, Electronics Engineering

Victor Karpenko, Laser Science Engineering, Mech. Eng. *Satish Kulkarni, New Technologies Engineering, Mech.

Eng.

Mark Mintz, Defense \& Nuclear Technology

Chuck Rockhold, Laser Science Engineering, Mech. Eng Bob Yamamoto, Applied Research Engineering, Mech. Eng 


\section{F. Assessment meeting agenda and presenters}

\section{December 6. Tours of IANSCE at IANL}

08:30

08:45

09:00

$10: 30$

12:00

13:15

$14: 30$

$14: 45$

16:00

08:00

08:15

$09: 15$

10:00

$10: 45$

$11: 30$

$12: 30$

14:00

$14: 20$

15:05

$15: 35$

$15: 35$

$16: 20$

$16: 50$

$17: 25$

14:00

14:15

$15: 15$

16:00

$16: 30$

$17: 25$
Visitors arrive at TA-53, MPF-8, Orange Box Introductions and presentation of agenda Tour of LAMPF

Tour of LNSC and WNR

Lunch in main cafeteria

ADPF and GTA tour

Travel to TSTA

TSTA tour, discussion of APT processing

Classified discussion of stockpile requirement
John Browne, Paul Lisowski, LANL

Earl Hoffman, LANL

Gary Russell, Paul Lisowski, LANL

George Lawrence, Joe Sherman, LANL

Will Fox, Dick Arlson, LANL

Pat Reardon, LANL

\section{December 7, Presentations at SNL, Albuquerque}

Introduction

Project status and overview Accelerator design overview He-3 target/processing overview SILC target/processing overview Demars, B\&W

Balance of plant, cost and schedule PEIS input and safety analysis overview
John Kelly, SNL

Roger Fisher, DOE

Dennis Slaughter, LLNL

Paul Lisowski, LANL

George Lawrence, LANL

Mike Cappiello, LANL

Greg Van Tuyle, Mike Todosow, BNL, Richard

Robert Taussig, Bechtel

LeAnn Miller, Susan Carson, SNL

Accelerator

Agenda/introduction

Beam dynamics and structures

Injector

Accelerating structure engineering

RF power systems

New front-end design concept

High-energy beam transport

Beam halo, beam losses
George Lawrence, LANL, Chair

Bob Garnett, LANL

Joe Sherman, LANL

Dale Schrage, LANL

Mike Lynch, LANL

Jim Billen, LANL

Barbara Blind, LANL

Tom Wangler, LANL

Target

Agenda/introduction

Physics of ${ }^{3} \mathrm{He}$ target

${ }^{3}$ He target mechanical layout

3 He structural analysis summary

Physics of SILC target

SILC target mechanical layout
Mike Cappiello, Chair

Gary Russell, LANL

Richard DeMars, B\&W

Dan Welnacht, LANL.

Michael Todosow, BNL

Richard DeMars, B\&W

December 8, Presentations at SNL, Albuquerque

Accelerator issues, balance of plant, RAM 
08:00

08:15

08:45

09:15

10:00

11:00

08:00

08:15

09:00

$09: 45$

09:45

10:30

11:15

13:00

13:15

14:15

15:00

16:00

13:00

13:15

13:30

14:15

14:35

15:15

$15: 45$

16:15

$17: 00$

09:00

13:00
Agenda/introduction

Other design issues (efficiency, availability)

Safety, machine protection, fault recovery

Accelerator risk reduction program

Basis for BOP design (cooling, shield, remote)

RAM methodology, model development
John Cunliffe, Bechtel, Chair

George Lawrence, LANL

George Lawrence, LANL

George Lawrence, LANL

Bob Taussig, Bechtel

Louis Guillebaud, LANL, Bob Younglbood, BNL

Target/blanket experiments

Agenda/introduction

${ }^{3} \mathrm{He}$ target thermal hydraulic design, expts

SILC radionuclide, $n / p$, and decay heat expts

$\mathrm{W}$ and $\mathrm{Pb} 800 \mathrm{MeV}$ radionuclide experiments

SILC materials experiments

Materials experiments and risk reduction plan

${ }^{3} \mathrm{He} \mathrm{n} / \mathrm{p}$ and $\mathrm{T} / \mathrm{p}$ physics tests, risk reduction
Greg Van Tuyle, BNL, Chair

Gordon Wilcutt, LANL

Lew Snead, BNL

John Ullmann, LANL

Lew Snead, BNL

Walt Sommer, LANL

George Morgan, LANL

ES\&H, GSRD

Agenda/introduction

Target safety, accidents

SNL analysis of safety aspects

Target release calculations

Environmental and safety regulator insights
John Kelly, SNL, Chair

Sewell Rose, LANL, Bob Youngblood, BNL

John Kelly, SNL

LeAnn Miller, SNL

Dennis Miller, SNL

Cost \& Schedule

Agenda/introduction

Pre-operational costs

Capital costs

Start-up/commissioning costs

Risk contingency calculations

Operating costs (staffing, mix, skills)

Overview of phased costs estimates

Overview of $3 / 8$ and phased sys schedules
Louis Guillebaud, LANL, Chair

John Cunliffe, Bechtel, Louis Guillebaud, LANL John Cunliffe, Bechtel

John Cunliffe, Bechtel, George Lawrence, LANL John Cunliffe, Bechtel

John Cunliffe, Bechtel, George Lawrence, LANL John Cunliffe, Bechtel, George Lawrence, Louis Guillebaud, LANL

John Cunliffe, Bechtel, George Lawrence, Louis Guillebaud, LANL

General session

Wrapup discussions

Paul Lisowski, LANL, Chair

December 9, Accelerator working group, LANL

Informal discussions of accelerator design

Adjourn 


\section{G. Bibliography of documents used to derive conclusions}

1. J. W. Landis, "Accelerator Production of Tritium (APT) ", Energy Research Advisory Board, review DOE/S-0074, February, 1990.

2. V.S. Rezendes, "The feasibility of using a particle accelerator to produce tritium ", United States General Accounting Office, GAO/RCED91-1 Accelerator Technology for Tritium, October 31, 1991.

3. S. D. Drell, "Accelerator production of tritium (APT) ", JASON- The Mitre Corporation, JSR-92-310, January, 1992.

4. E. J. Moniz, "APT review at MIT", November 23, 1994, Personal communication.

5. R. L. Steinhoff, P. W. Lisowski, T. W. Ward, T. Calocci, M. Cappiello, C. Czajkowski, G. Morgan, R. Salzbrenner, L. Snead, "Accelerator Production of Tritium (APT) Test Strategy ", U.S. Department of Energy, Defense Programs, Office of Reconfiguration, June, 1994.

6. "Accelerator Topical Report ", LANL, LACP-94-48, March, 1994.

7. "Accelerator topical report ", LANL, LA12668-MS Volume II, September, 1993.

8. P. W. Lisowski, "3 $\mathrm{He}$ target/blanket topical report ", LANL, LA-12670-MS, Volume II, September 30, 1993.

9. P. W. Lisowski, "3 He target/blanket topical report ", LANL, LA-12670-MS, Volume I, September 30, 1993.

10. "APT ${ }^{3}$ He target/blanket topical report ", LANL, LA-CP-94-27 Vol. 1 Rev. 1, March, 1994.

11. "APT ${ }^{3}$ He target/blanket topical report ", LANL, LA-12670-MS Voll I Rev. 1, September 30, 1993.

12. "APT ${ }^{3}$ He target/blanket topical report ", LANL, LA-12670-MS Vol. I Rev. 1, September 30 , 1993.
13. "APT ${ }^{3}$ He target/blanket tritium extraction facility technical report ", LANL, LAUR-93-3113, September, 1993.

14. "APT Radionuclide Production Experiment Technical Report ", LANL, LA-UR-933448, September, 1993.

15. "APT tritium extraction facility technical report ", LANL, LA-UR-93-3113, September, 1993.

16. "APT Technology Development Program Four-year Plan (FY1995 through FY1998) ", LANL, LA-APT-4 Rev. 0, July 30, 1993.

17. "APT Radionuclide production experiment technical report ", LANL, LA-UR-933448, September, 1993.

18. "Balance of plant topical report ", LANL, LA-CP-94-26, March, 1994.

19. "APT cost and schedule report -preconceptual design- ", LANL, LA-CP-94-28, March, 1994.

20. "APT Technology Development Program Four-Year Plan ", LANL, executive summary-June 7, 1993.

21. L. A. Miller, G. A. Greene, B. E. Boyack, "Accelerator production of tritium programmatic environmental impact statement input submittal ", Sandia National Laboratories, SAND93-2094, November 22, 1994.

22. "General safety requirements document for the accelerator production of tritium facility ", U. S. Department of Energy, APT-GSR-0001-00, June, 1994.

23. G. Van Tuyle, "APT briefing to the Lawrence Livermore National Laboratory Team", 30 November, 1994, Personal communication.

24. P. V. Livdahl, "The Livermore MTA project and its influence on modern linacs", 1970s, Personal communication. 
25. C. M. VanAtta, "A brief history of the MTA project ", LLNL, UCRL-79151,

26. T. Taylor, "High-current dc microwave ion sources", Rev. Sci. Inst. 63, 2507-12 (1992).

27. T. O. Brun, C. A. Beard, L. L. Daemen, E. J. Pitcher, G. J. Russell, W. B. Wilson, "LAHET code system/CINDER' 90 validation calculations and comparison with experimental data", Twelfth Meeting of the International Collaboration on Advanced Neutron Sources, 24-28 May, (1993), Cosener's House, Abingdon, Oxfordshire, UK,

28. G. J. Van Tuyle, M. Todosow, D. M. Cokinos, C. Czajkowski, E.-M. Franz, G. Greene, P. Kroeger, N. Tutu, R. Youngblood, 'Preliminary topical report for revision-1 of a preconceptual design for the spallation-induced lithium conversion (SILC) target for the accelerator production of tritium (APT) ", Brookhaven National Laboratory, ATD/APT94-0008 (Rev. 0), June 24, 1994.

29. L. L. Daemen, E. J. Pitcher, "LCS/TIERCE tritium benchmark", October 14, 1993, Personal communication.

30. G. Morgan, G. Butler, M. Cappiello, S. Carius, et al., "LANL Sunnyside experiment study: Study of neutron production in accelerator-driven targets", 1994, Personal communication.

31. T. E. Ward, J. Frehaut, S. Leray, J. L. Morgan, C. L. Snead, "Integral neutron measurements for APT", December, 1994, Personal communication.

32. T. E. Ward, "Recent advances in integral neutron yield measurements", CEA/DAM-DOE meeting, September, (1994),

33. R. G. Vassil'kov, V. I, Yurevich, "Neutron emission from an extended lead target under the action of light ions in the $\mathrm{GeV}$ region", ICANSXTA International Collaboration on Advanced Neutron Sources, October 22-26, (1990), KEK, Tsukuba,

34. V. A. Nikolaev, V. I. Yurevich, R. M. Yakovlev, R. G. Vassil'kov, Neutron production in thick lead target by $1-3.7 \mathrm{GeV}$ protons and deuterons", ICANS-XIA International
Collaboration on Advanced Neutron Sources, October 22-26, (1990), KEK, Tsukuba,

35. G.S. Bauer, "Targets for neutron beam spallation sources ", Kernforschungsanlage Julich Gmbh, Jui-Conf-34, January, 1980.

36. M. J. Clausen, T. A. Hendrickson, "Accelerator production of tritium requirements document ", U.S. Department of Energy, Office of New Production Reactors, APT-Rd-0001-00, June, 1992.

37. J. H. Billen, S. Nath, H. Takeda, R. L. Wood, L. M. Young, "New design concepts for APT", LLNL Review of APT, (1994), Sandia National Laboratory, Albuquerque, NM,

38. C. S. Landram, "Thermal-hydraulic performance of the GETR emergency cooling system-experimental and analytical considerations ", General Electric Co., Report NEDO-12626, Class 1, April, 1976.

39. R. D. Watson, "High heat flux issues for plasma facing components in fusion reactors", 1992, Personal communication.

40. G. P. Celata, M. Cumo, "A review of recent experiments and prediction aspects of burnout at very high heat fluxes", Energia Nucleare \&, (1991).

41. Y. A. Zeigarnik, N. P. Privalov, A. I. Klimov, "Critical heat flux with boiling of subcooled water in rectangular channels with one side supply of heat", Thermal Engineering 28, 4043 (1981).

42. C. S. Landram, "Microchannel flow boiling mechanisms leading to burnout", ASME Heat Transfer in Electronics Systems HTD 292. 129-136 (1994).

43. J. Maltby, "MONTE3D ", LLNL, UCRLMA-112192, February, 1993.

44. A. Shapiro, "TOPAZ3D", LLNL, UCID290484, August, 1985.

45. J. Halquist, "NIKE3D ", LLNL, UCRLMA-105268, January, 1991. 